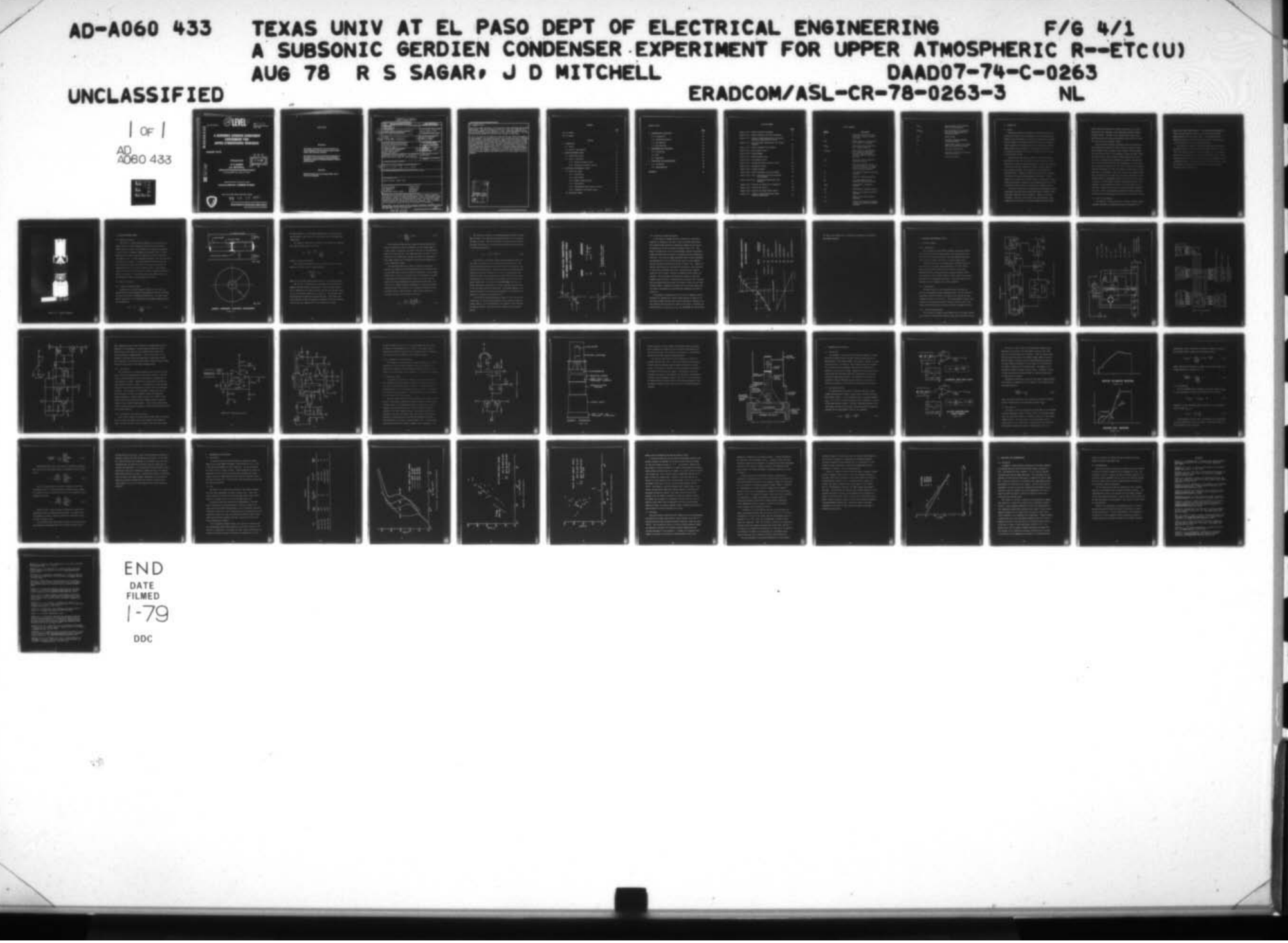




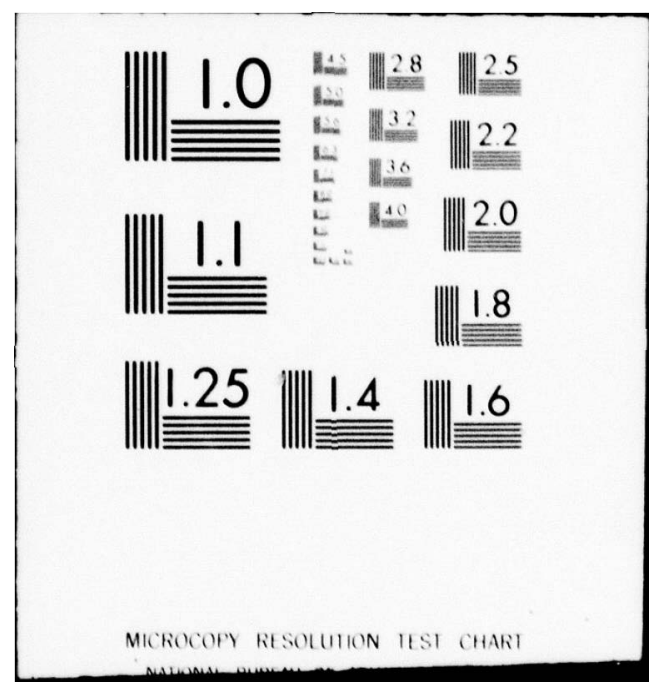




\section{A SUBSONIC GERDIEN CONDENSER EXPERIMENT FOR UPPER ATMOSPHERIC RESEARCH}

\section{AUGUST 1978}

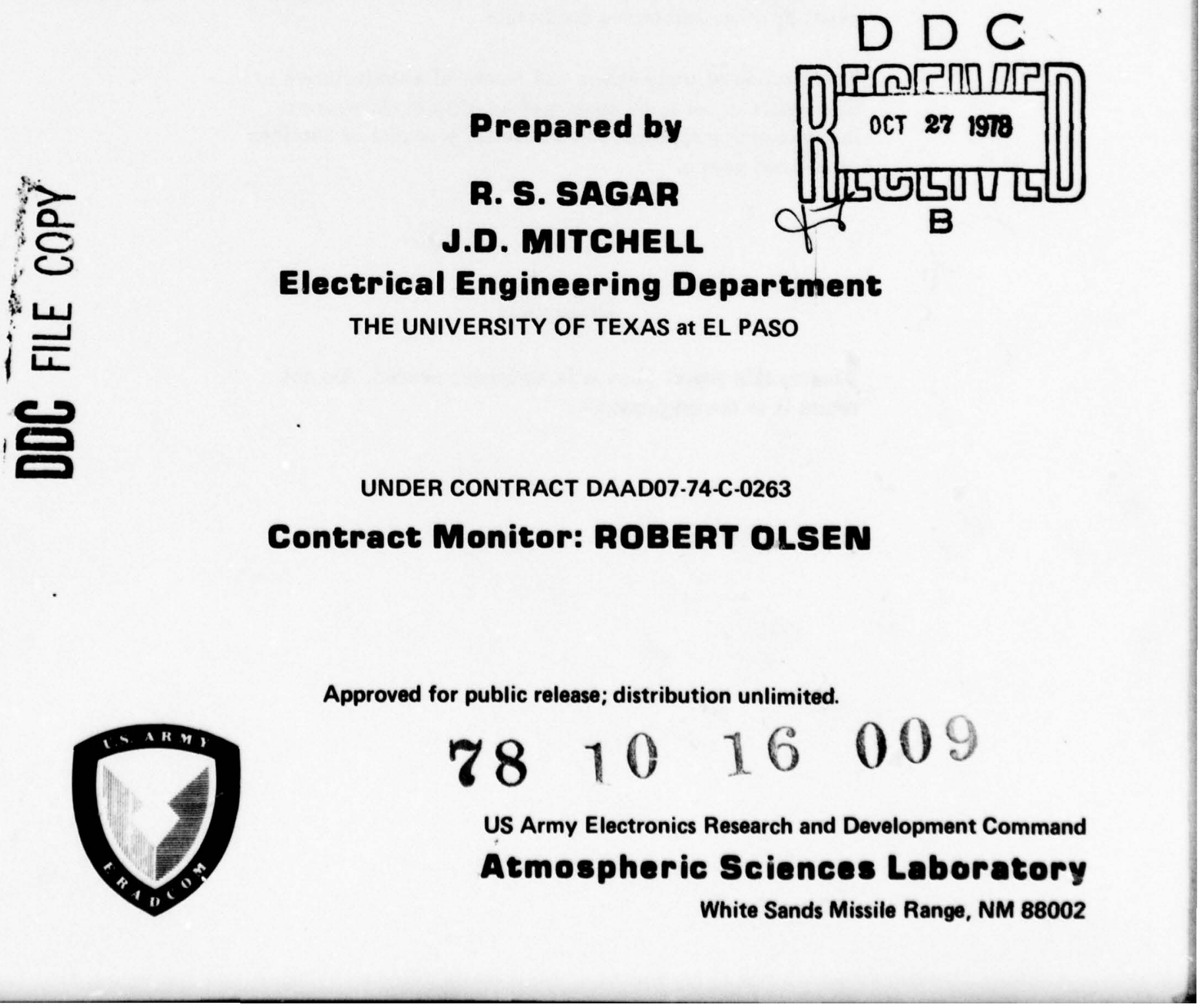




\section{NOTICES}

\section{Disclaimers}

The findings in this report are not to be construed as an official Department of the Army position, unless so designated by other authorized documents.

The oitation of trade names and namea of manufacturers in this report is not to be construed as official Covernment indorecment or approval of commercial produote of services roloreseed herein.

\section{Dispesition}

Destroy this report when it is no longer needed. Do not return it to the originator. 


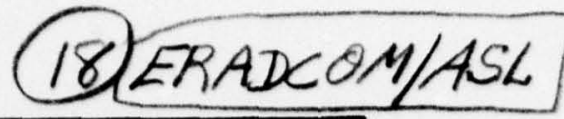

SECUNITY CLASSIFICATION OF THIS PAGE (When Date Entored

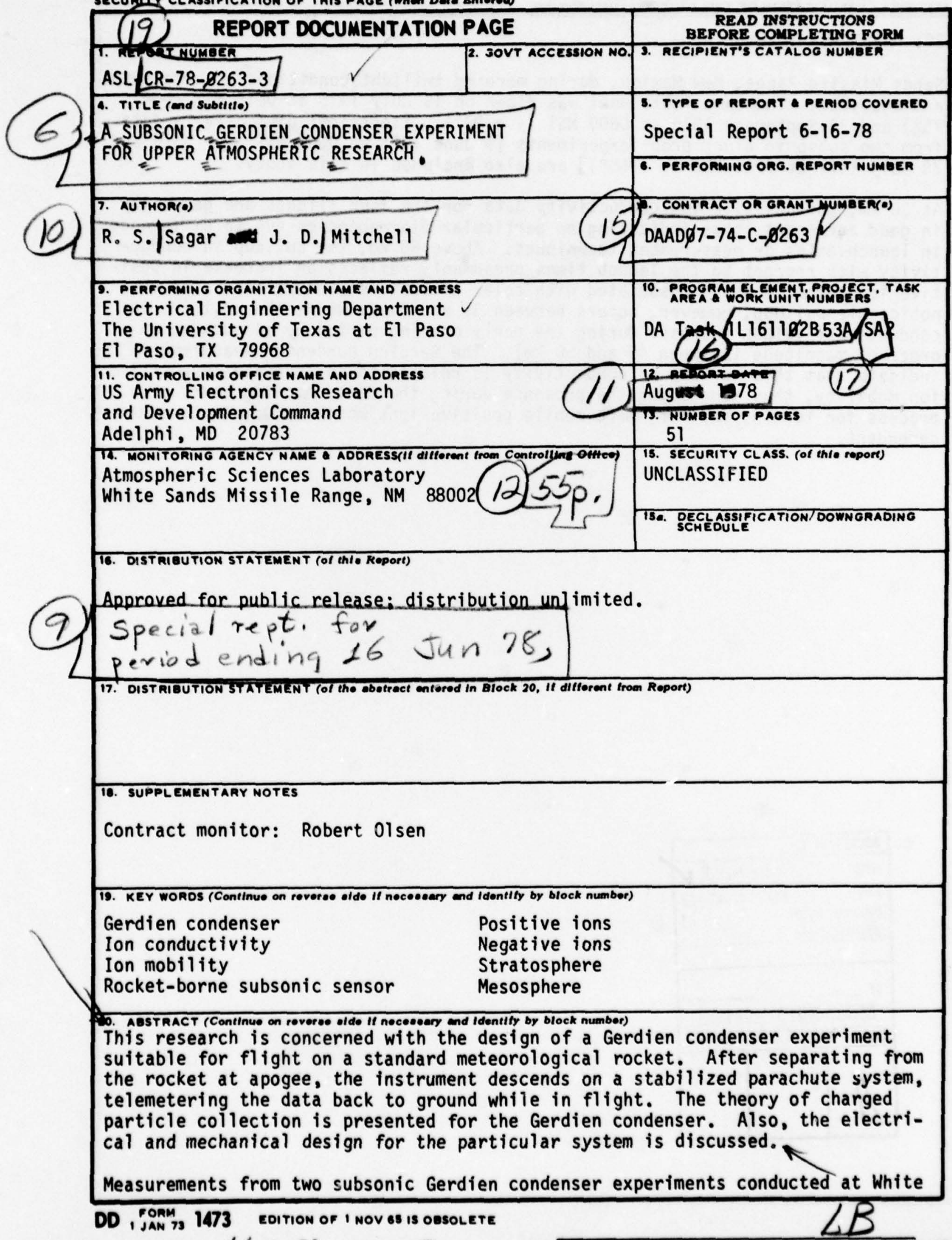




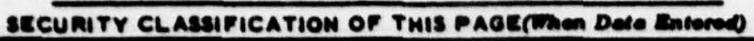

\section{ABSTRACT (cont)}

Sands Missile Range, New Mexico, during morning twilight conditions are presented and analyzed. The same instrument was flown on 15 July 1975 at 0618 MST ( $x=$ $\left.75^{\circ}\right)$ and 26 September 1975 at 0600 MST $\left(x=90^{\circ}\right)$. Electrical conductivity data from two subsonic blunt probe experiments [ 9 June 1971 at 0809 MST $\left(x=53^{\circ}\right)$ and 28 July 1971 at 0705 MST $\left(x=68^{\circ}\right)$ ] are also included in this study.

At $30 \mathrm{~km}$, the positive ion conductivity data for the four flights are generally in good agreement, thus indicating no particular discrepancies due to differences in launch dates or measurement techniques. Above $60 \mathrm{~km}$, the buildup in conductivity with respect to the launch times presumably reflects an increase in positive ion number density associated with solar ultraviolet ionization. The most noticeable buildup, however, occurs between 35 and $60 \mathrm{~km}$ where the positive ion conductivity values increase during the early morning period by as much as an order of magnitude (between 45 and $50 \mathrm{~km}$ ). The Gerdien condenser measurements indicate that this buildup in conductivity is related to an increase in positive fon mobility, thus suggesting the presence during the early morning hours of a process for forming smaller, more mobile positive ions which appear to be solar dependent.

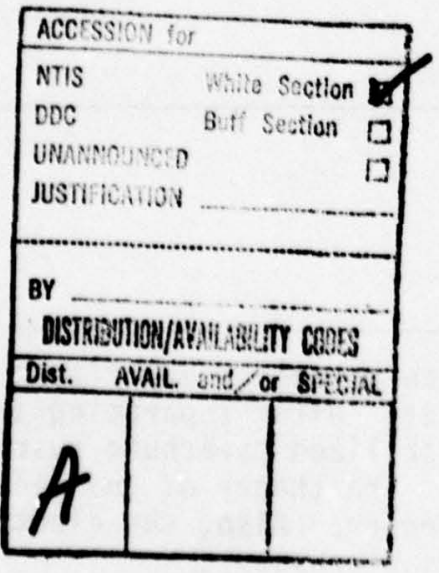




\section{CONTENTS}

$\underline{\text { Page }}$

LIST OF FIGURES

LIST OF SYMBOLS

\section{CHAPTERS}

1. INTRODUCTION

1.1 Review

6

1.2 Scope of this Research

2. GERDIEN CONDENSER THEORY

2.1 General Description

2.2 Theory of Operation 10

2.2.1 Single Ion Mobility Case 10

2.2.2 Multiple Ion Mobility Species 16

3. ELECTRICAL AND MECHANICAL DESIGN 19

3.1 Electrical Design

3.1.1 Introduction 19

3.1.2 Power Supp1y 19

3.1.3 Sweep Voltage Generator 19

3.1.4 Electrometer 24

3.1.5 Voltage-Pulse Rate Converter Circuit 24

3.1.6 Transmitter and Antenna System 
Contents (cont)

\section{Page}

4. TELEMETRY/DATA ACQUISITION 32

4.1 Introduction 32

4.2 Callbration Wave form 32

4.3 Data Waveform 34

4.4 Data Reduction 36

5. MEASUREMENTS AND DISCUSSION 39

5.1 Introduction 39

$\begin{array}{lll}5.2 & \text { Data } & 39\end{array}$

5.3 Discussion $\quad 44$

6. CONCLUSIONS AND RECOMMENDATIONS 48

6.1 Conclusions 48

$\begin{array}{llr}6.2 & \text { Recommendations } & 49\end{array}$

$\begin{array}{lr}\text { RFFERENCES } & 50\end{array}$ 


\section{LIST OF FIGURES}

Figure (1-1) - Gerdien Condenser Photograph

F1gure (2-1) - Gerdien Condenser Electrode Arrangement 11

Figure (2-2) - Current-Voltage Characteristic for Gerdien Condenser--Single Mobility Species

Figure (2-3) - Current-Voltage Characteristic for Gerdien Condenser

F1gure (3-1) - Gerdien Condenser Block D1agram 20

Figure (3-2) - Power Supply Circult 21

Figure (3-3) - Wiring Diagram 22

Figure (3-4) - Sweep Voltage Circuit 23

Figure (3-5) - Electrometer C1rcuit 25

Figure (3-6) - Voltage-Pulse Rate Converter Circult 26

Figure (3-7) - Transmitter C1rcuit 28

F1gure (3-8) - Gerdien Condenser 29

Figure (3-9) - Gerdien Condenser Collector Assembly 31

Figure (4-1a, 4-1b) - Calibration and Operating Modes Block D1agram

Figure $(4-2 a, 4-2 b)-$ Calibration Waveform and Data Wave form

F1gure (5-1) - Positive Ion Conductivity (Composite) 41

Figure (5-2) - Positive Ion Mobility 42

Figure (5-3) - Positive Ion Charge Number Density 43

F1gure (5-4) - Secant of Solar Zenith Angle Versus
Positive Conductivity 
Symbo1

C

$\mathbf{E}(\mathbf{r})$

(1)

$\left(1_{ \pm}\right)_{\text {Data }}$

$1_{\text {st }}$

$1 \pm$

$k_{ \pm}$

$\ell$

$\mathbf{N}_{ \pm}$

$\mathbf{R}_{\text {cal }}$

$\mathbf{R}_{\mathbf{f}}$

$\mathbf{r}_{1}$

$r_{0}$

$<$ <

\section{Definitions}

Capacitance between the inner (collector) and outer (return) electrodes

Radial component of the electric field inside the condenser

Input current to the electrometer during calibration

Input current to the electrometer during the flight/data portion of the instrument's operation (subscript indicates polarity)

Saturation current (subscript indicates polarity)

Collection current, used to describe current due to charged particle collection only (subscript indicates polarity)

Ion mobility (subscript indicates polarity)

Length of collector electrode

Ion charge number density (subscript indicates polarity)

Electrometer's calibration resistor

Electrometer's feedback resistor

Radius of the inner (collector) electrode

Radius of the outer (return) electrode

Average flow velocity associated with an ion entering the Gerdien condenser 
(v)

cal

$\left(v_{ \pm}\right)_{\text {Data }}$

$V(t)$

$\mathbf{v}_{\mathbf{s} \pm}$

$v_{r}$

$\varepsilon$

$\sigma_{ \pm}$

$x$
Output voltage of the electrometer during calibration

Output voltage of the electrometer during flight (subscript indicates polarity)

Sweep voltage

Saturation voltage (subscript indicates polarity)

Radial drift velocity for charged particles inside the aspirator

Free space permittivity

Electrical conductivity (subscript indicates polarity)

Solar zenith angle 


\section{INTRODUCTION}

\subsection{Review}

The current interest in atmospheric research with respect to Ionization processes in the stratosphere and lower mesosphere has resulted in the development of specialized instrumentation systems. One such system is the Gerdien condenser which uses a cylindrical collector geometry for measuring electrical conductivity, charge number density and ion mobility. The instrument is named for

H. Gerdien who presented the theory of charge particle collection for this device in 1905 .

Early work with the Gerdien condenser included ion mobility experiments at sea level as reported by Israel and Schulz (1933). Balloon borne Gerdien condenser experiments for measuring electrical conductivity have been conducted by Stergis, Coroniti, Nazarek, Kota, Seymour and Werme (1955), Woessner and Cobb (1958) and Paltridge (1965). Kraakevik (1958) utilized the Gerdien condenser for electrical conductivity measurements on aircraft. In this research, the accumulation of static charge on wing surfaces during flight necessitated an analysis of the resulting electric field and the effect it might have on the collection of charged particles.

Electrical conductivity, ion mobility and charge number density measurements have also been obtained from Gerdien condenser rocket experiments employing either supersonic or subsonic collection techniques. Electrical conductivity data from supersonic rocket flights have been reported by Bourdeau, Whipple and Clark (1959). 
Conley (1974) has published ion mobility and positive ion concentration data from supersonic rocket experiments using the Gerdien condenser system. Included in this research was a study of how the collected positive ions would possibly be affected by the shock wave associated with supersonic flight.

Subsonic Gerdien condenser experiments flown on parachute systems deployed from rockets have been conducted by Pederson (1964), Rose and Widdel (1972), Farrokh (1975), Croskey (1976) and Widdel, Rose and Borchers (1976). The experiments of Rose and Widdel (1972) and Widdel et al. (1976) utilized a Gerdien condenser with an air flow meter accompanying the instrument in a parallel configuration. The air flow data obtained from their experiments in the laboratory and on parachutes indicated that the ion flow velocity for a Gerdien condenser descending on a stabilized parachute system could be estimated from the instrument's radar fall velocity data [Widdel (1975)]. Thus, the ability to use these radar data greatly simplifies the instrument design by eliminating the need for such an air flow measuring device. For the Gerdien condenser experiments reported in this research, a cross parachute was used on the first flight (July 15, 1975) and a starute was flown with the second experiment (September $26,1975)$. Both of these parachute systems have been developed to minimize payload swing typically associated with decelerator systems.

\author{
1.2 Scope of this Research \\ The objective of this research was to design a subsonic Gerdien \\ condenser experiment for measuring electrical conductivity, ion
}


mobility and charge number density. The instrument was designed for flight on rocket systems currently in use by the Meteorological

Rocket Network such as the Arcas rocket. As discussed earlier, a stabilized parachute system was used since the ion flow velocity was to be calculated from the instrument's radar data.

The two Gerdien condenser experiments reported in this research were both conducted at White Sands Missile Range, New Mexico. A picture of the Gerdien condenser is shown in Figure (1-1). The instrument was first launched on July 15, 1975 at 0618 MST $\left(x=75^{\circ}\right)$. After being successfully recovered, it was flown again on September 26, 1975 at $0600 \mathrm{MST}\left(x=90^{\circ}\right)$. The launch times were selected in order to study the ionization variability in the midlatitude, middle atmosphere during the early morning period. 

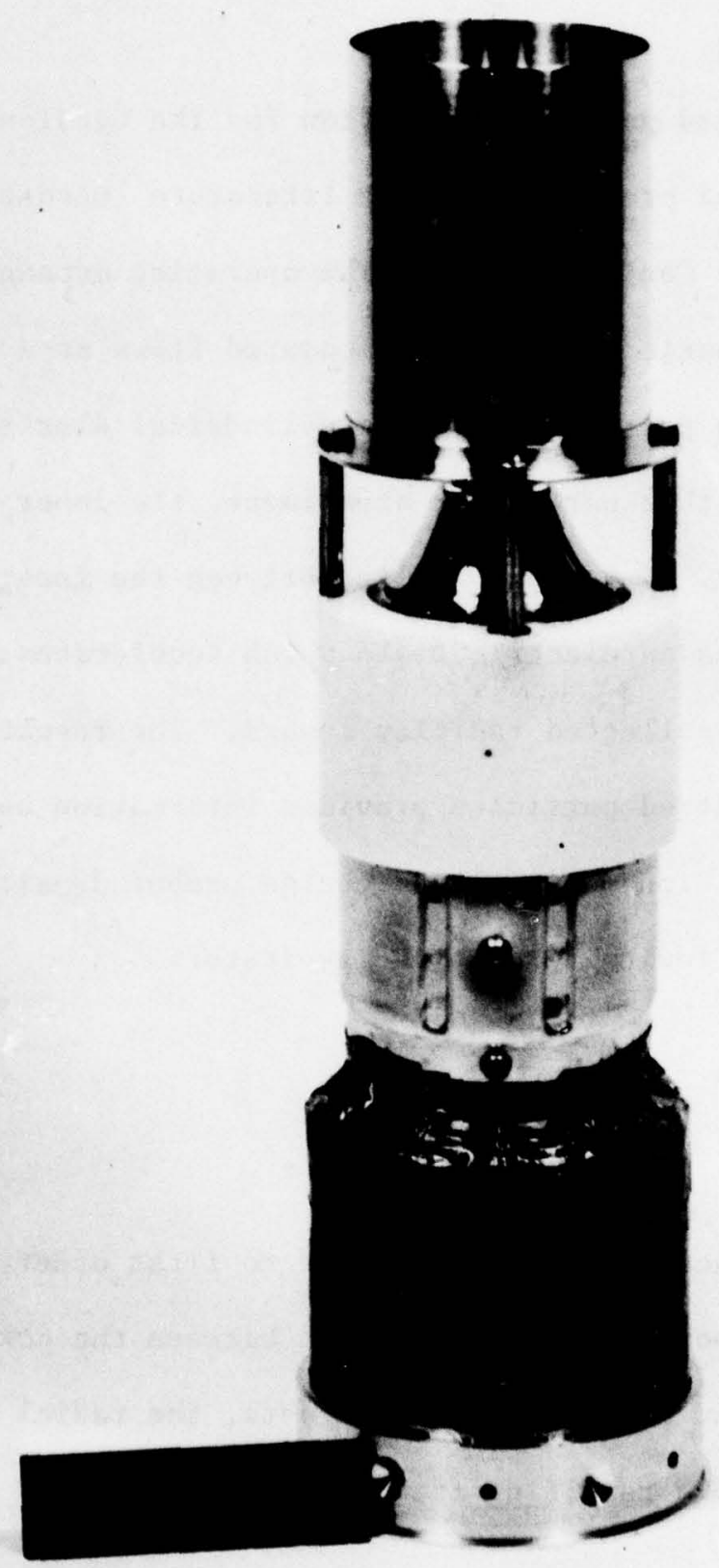

Figure (1-1) - Gerdien Condenser 


\section{GERDIEN CONDENSER THEORY}

\subsection{General Description}

The theory of charged particle collection for the Gerdien condenser has been discussed previously in the literature [Gerdien (1905); Pederson (1964); Conley (1974)]. The operating arrangement is such that the atmospheric sample to be measured flows at a determined velocity through a pair of concentric cylindrical electrodes (see Figure (2-1)). In this particular experiment, the inner electrode is used as the collector. A voltage applied between the inner and outer electrodes produces an electric field which accelerates the charged particles to be collected radially inward. The resulting current of collected charged particles provides information about the electrical conductivity, ion mobility and charge number density of the atmospheric sample flowing through the aspirator.

\subsection{Theory of Operation}

\subsubsection{Single Ion Mobility Case}

Assuming that Laplace's equation is valid to first order for describing the voltage potential in the region between the collecting and return electrodes and neglecting edge effects, the radial component of the electric field resulting from a voltage $V$ applied between the electrodes is:

$$
E(r)=\frac{V}{r} \frac{1}{\ln \left(\frac{r_{0}}{r_{1}}\right)} ; \quad r_{1}<r<r_{0}
$$



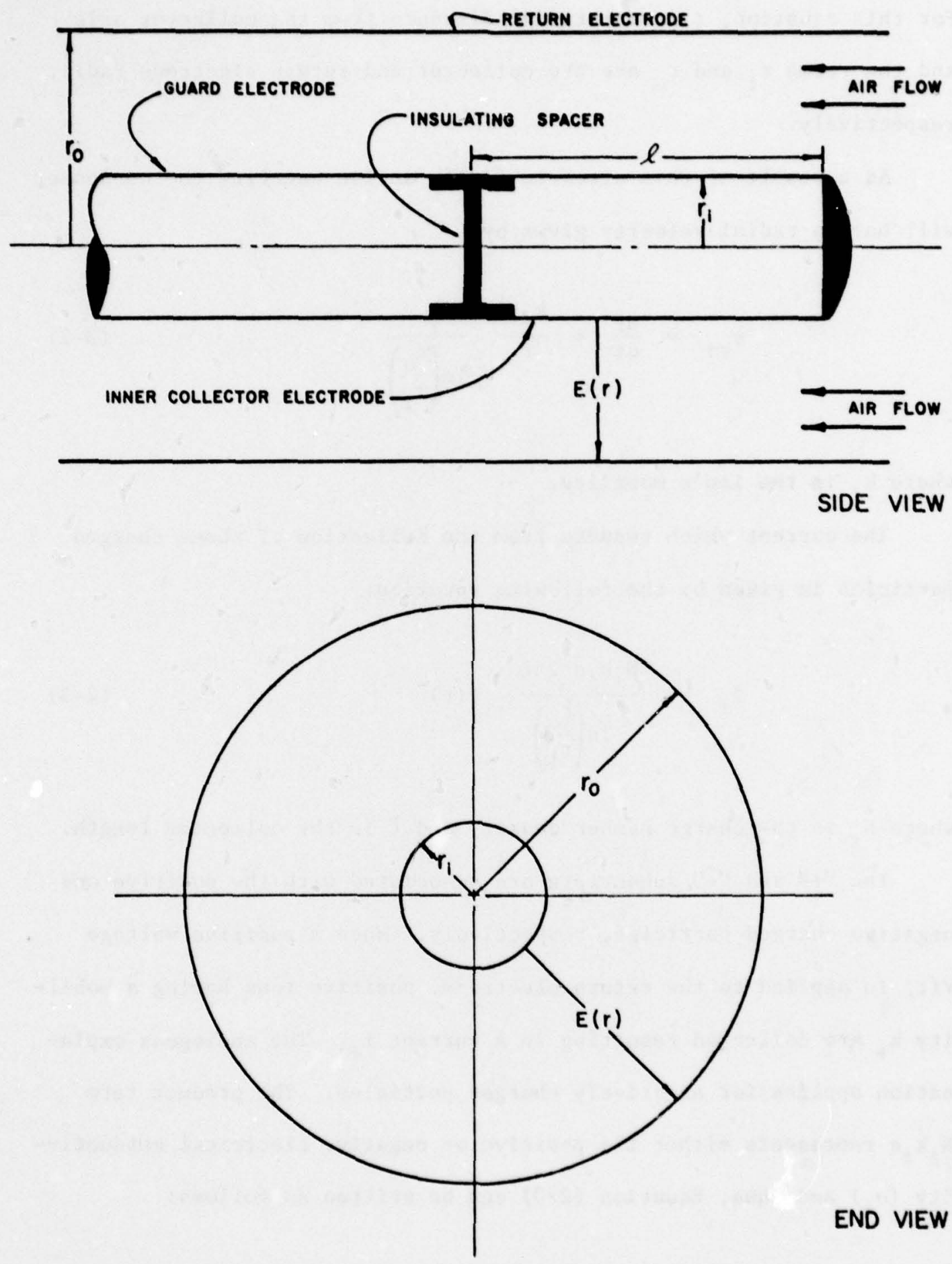

END VIEW

\section{GERDIEN CONDENSER ELECTRODE ARRANGEMENT}

FIGURE (2-1) 
For this equation, $r$ is the radial distance from the collector axis and the terms $r_{i}$ and $r_{0}$ are the collector and return electrode radii, respectively.

As a result of this electric field, an ion entering the condenser will have a radial velocity given by:

$$
v_{r \pm}=\frac{d r}{d t}=\frac{k_{ \pm} v}{r} \frac{1}{\ln \left(\frac{r_{0}}{r_{i}}\right)}
$$

where $k_{ \pm}$is the ion's mobility.

The current which results from the collection of these charged particles is given by the following equation:

$$
i_{ \pm}=\frac{\mathrm{N}_{ \pm} \mathrm{k}_{ \pm} \mathrm{q} 2 \pi \ell}{\ln \left(\frac{\mathrm{r}_{\mathrm{o}}}{\mathrm{r}_{\mathrm{i}}}\right)} \mathrm{V}(\mathrm{t})
$$

where $N_{ \pm}$is the charge number density and $\ell$ is the collector length. The "+" and "-" subscripts are associated with the positive and negative charged particles, respectively. When a positive voltage $V(t)$ is applied to the return electrode, positive ions having a mobility $k_{+}$are collected resulting in a current $i_{+}$. The analogous explanation applies for negatively charged particles. The product term $\mathrm{N}_{ \pm} \mathrm{k}_{ \pm} \mathrm{q}$ represents either the positive or negative electrical conductivity $\left(\sigma_{ \pm}\right)$and thus, Equation $(2-3)$ can be written as follows: 


$$
1_{ \pm}=\frac{2 \pi \ell}{\ln \left(\frac{{ }_{0}}{r_{1}}\right)} \sigma_{ \pm} V(t)
$$

This expression describes the current collection when the condenser is operating in what is referred to as the "linear region." In this region of operation, only some of the ions in the atmospheric sample are being collected. The resulting current is seen to be proportional to fon conductivity and thus, operating the instrument in this region enables one to determine the positive and negative electrical conductivity values.

The operating condition for which all ions of one polarity entering the condenser are collected regardless of the initial velocity and radial point of entry is known as saturation. From an experimental point of view, it is important that the instrument is capable of operating in the saturation mode if one is to extract the ion mobility and charge number density information from the data. For the case of a Gerdien condenser descending on a stabilized parachute system, the axial flow velocity $(\langle v\rangle)$ through the condenser can be estimated from the radar fall data. This situation permits the saturation voltage to be specified as follows:

$$
v_{s \pm}=\frac{\left(r_{0}^{2}-r_{i}^{2}\right) \ln \left(\frac{r_{0}}{r_{i}}\right)\langle v\rangle}{2 k_{ \pm} \ell}
$$


The saturation voltage is the minimum voltage necessary to assure that all lons of one polarity entering the aspirator are collected by the Inner electrode. When the instrument is operating in the saturation mode, the current of collected charged particles may be specified in the following equation:

$$
i_{s \pm}=n\left(r_{0}^{2}-r_{i}^{2}\right) N_{ \pm} q\langle v>
$$

The features of the linear region and the saturation region for the single ion mobility case are illustrated in Figure (2-2). The current-voltage characteristic shows the collection of positive ions, electrons and negative ions. Electrons are much more mobile than the negative ions and are saturated out at such a low voltage that the electron current causes an apparent step discontinuity at the origin. The remaining ions, both positive and negative, are collected in the manner illustrated. In the linear regions (1) and (1), the slopes or current derivatives with respect to voltage $\left(d i_{+} / d V\right)$ are proportional to the Ion conductivities as illustrated. Regions (2) and (B) depict the saturation regions and illustrate the dependence of the positive and negative ion currents on the product $N_{ \pm}\langle v\rangle$.

The current-voltage relationship in Figure $(2-2)$ is for the simplified case of lons of the same polarity having comparable mobility values; however, in actual operation it is possible to have different Ion mobility species. This case will be covered in the following section. 

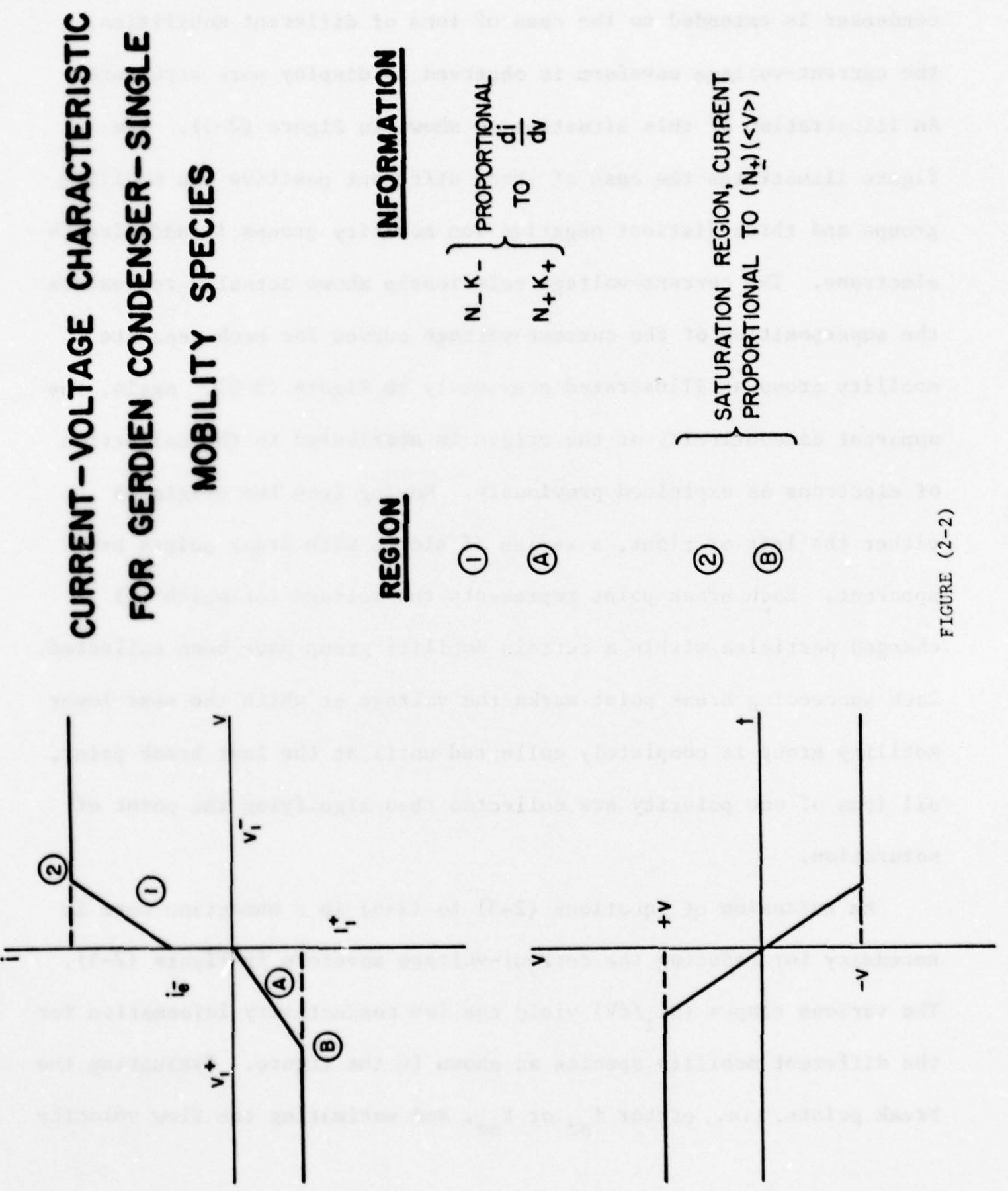


\subsubsection{Multiple Ion Mobility Species}

If the theory of charged particle collection for the Gerdien condenser is extended to the case of ions of different mobilities, the current-voltage waveform is observed to display more structure. An fllustration of this situation is shown in Figure (2-3). The figure illustrates the case of three different positive ion mobility groups and three distinct negative ton mobility groups in addition to electrons. The current-voltage relationshp shown actually represents the superposition of the current-voltage curves for each separate mobility group as illustrated previously in Figure (2-2). Again, the apparent discontinuity at the origin is attributed to the collection of electrons as explained previously. Moving from the origin to either the left or right, a series of slopes with break points are apparent. Each break point represents the voltage for which all charged particles within a certain mobility group have been collected. Each succeeding break point marks the voltage at which the next lower mobility group is completely collected until at the last break point, all lons of one polarity are collected thus signifying the point of saturation.

An extension of Equations (2-3) to (2-6) in a summation form is necessary for reducing the current-voltage waveform in Figure (2-3). The various slopes $\left(\mathrm{di}_{ \pm} / \mathrm{dV}\right)$ yield the ion conductivity information for the different mobility species as shown in the figure. Evaluating the break points, $1 . e .$, efther $1_{s \pm}$ or $v_{s \pm}$, and estimating the flow velocity 


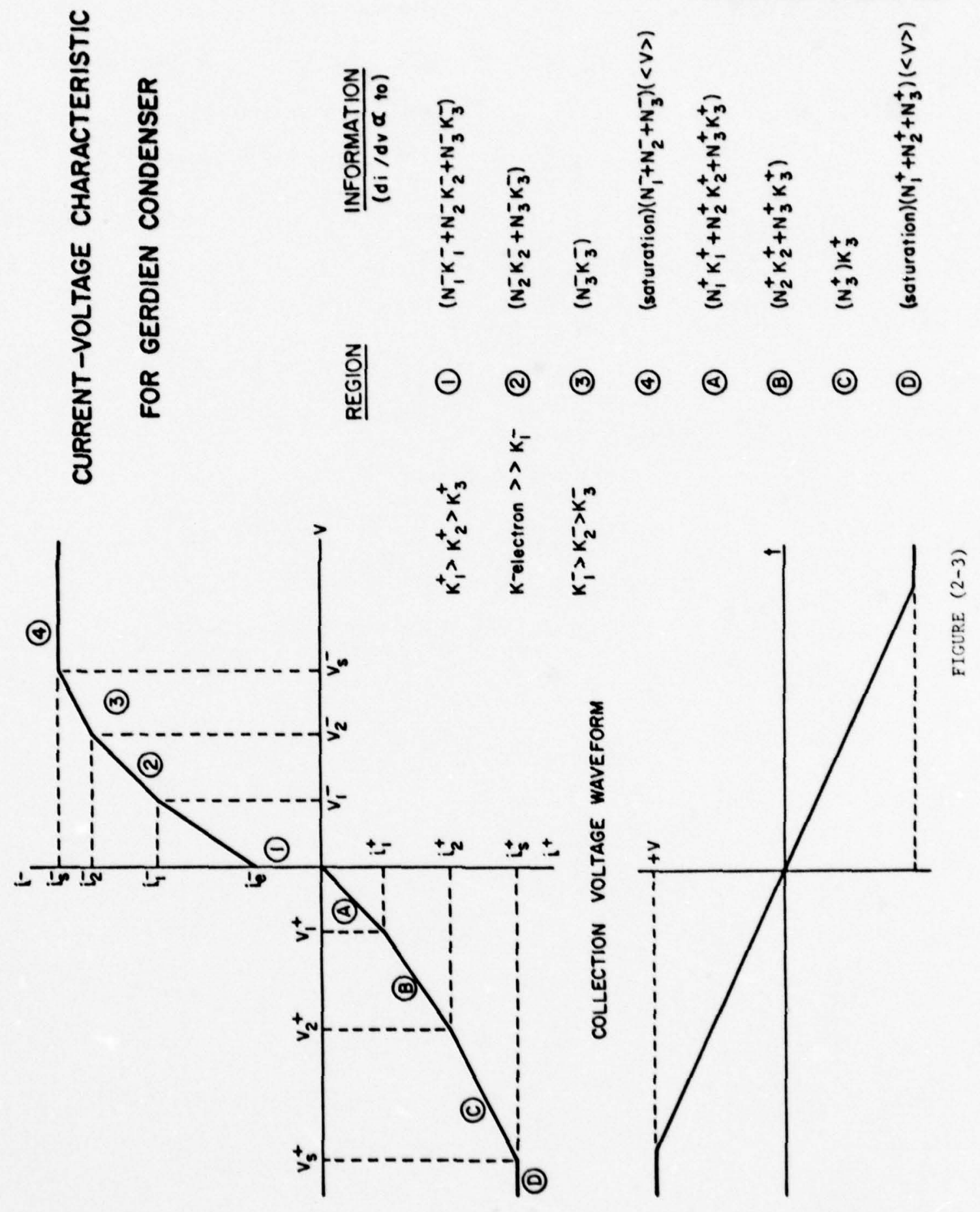


<v> will in turn enable one to evaluate the different ion mobilities and number densities. 


\section{ELECTRICAL AND MECHANICAL DESIGN}

\subsection{Electrical Design}

\subsubsection{Introduction}

The electronics for the Gerdien condenser include the internal power supply, the sweep voltage generator, the voltage-pulse rate converter and the telemetry system. The block diagram description of the Gerdien condenser electronics is shown in Figure (3-1).

A detailed analysis of the antenna system [Cuffin (1965)] and the operation of the power supply [ECOM Report No. 5144 (1967)], sweep voltage generator [Hale and Hoult (1965)], electrometer [Zimmerman (1971)], voltage-pulse rate converter [Pontano (1970)] and transmitter [Hale and Hoult 1965)] circuitry have been discussed previously in the designated references. A brief description of the function of these components will now be presented.

\subsubsection{Power Supply}

The power supply is a self-contained system utilizing four 1.25-volt rechargeable, nickel cadmium batteries. The batteries and associated converter circuitry (see figure (3-2)) provide de supply voltages of $+110 \mathrm{~V},+5 \mathrm{~V}$ and $-20 \mathrm{v}$. The wiring diagram in Figure (3-3) shows the pin connections used with the power supply as well as the wiring connections and color code for the Gerdien condenser circuitry.

\subsubsection{Sweep Voltage Generator}

The collection or sweep voltage (Figure (3-4)) is actually applied to the return electrode with reference to the inner collecting electrode. 


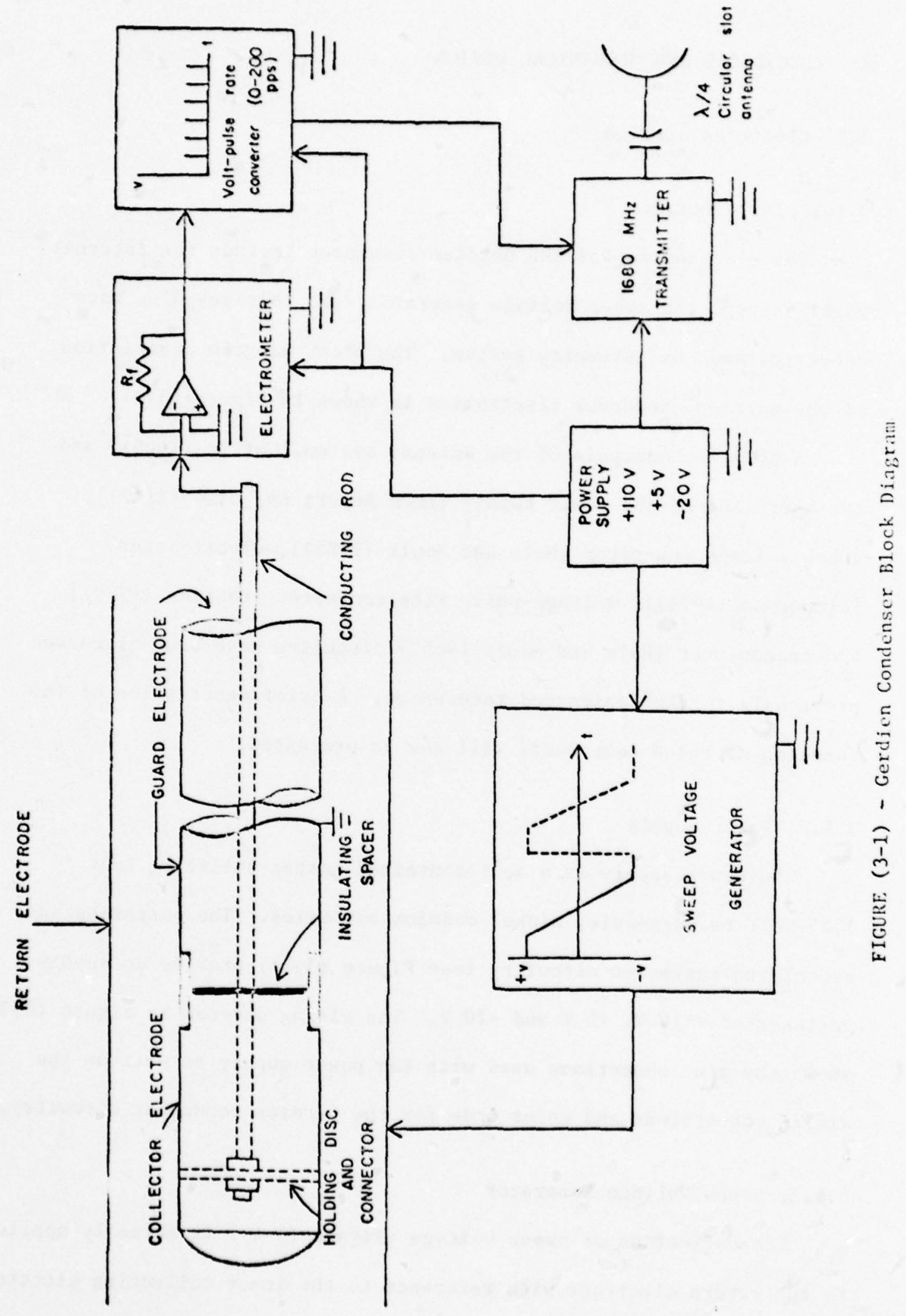



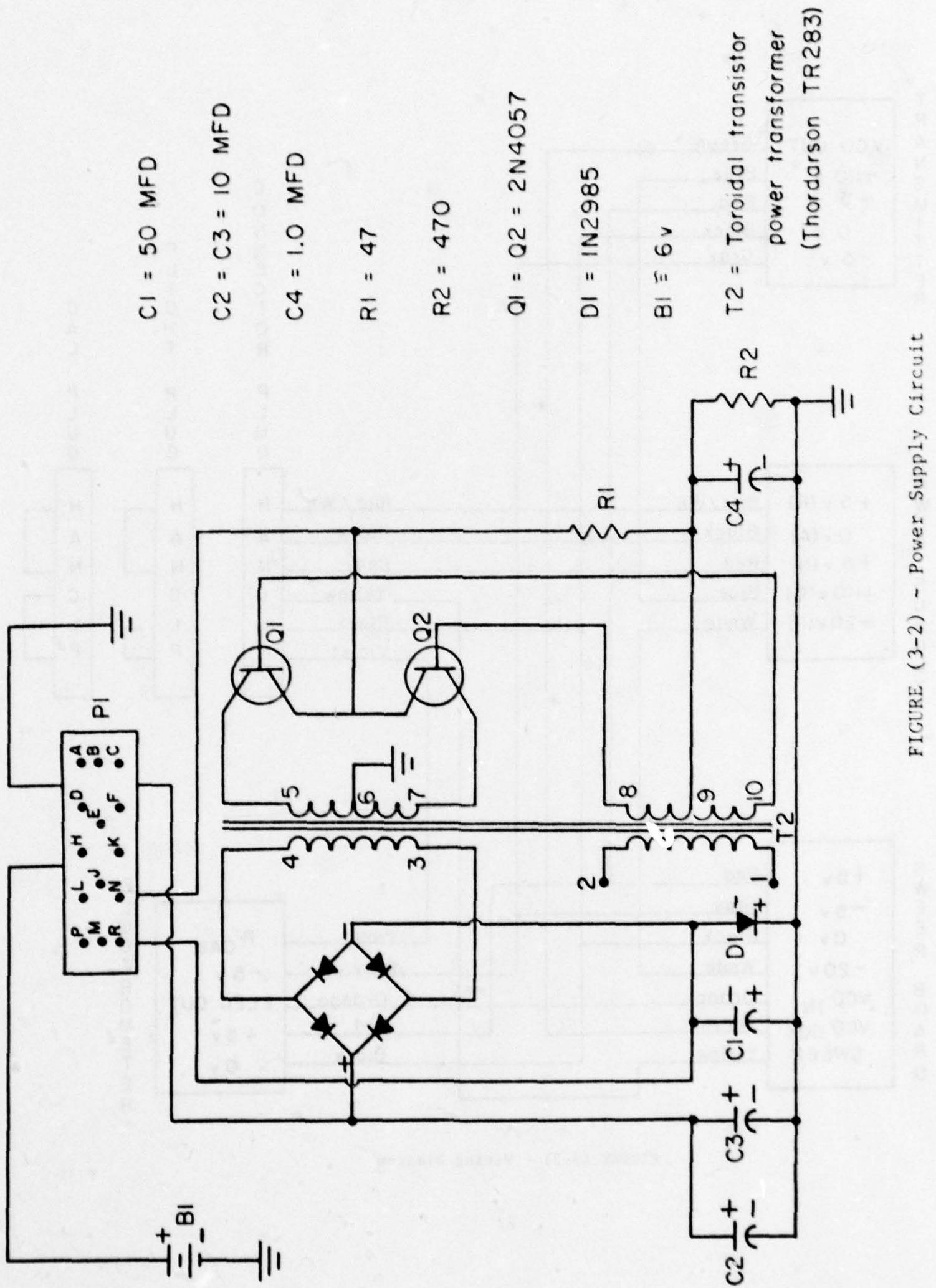


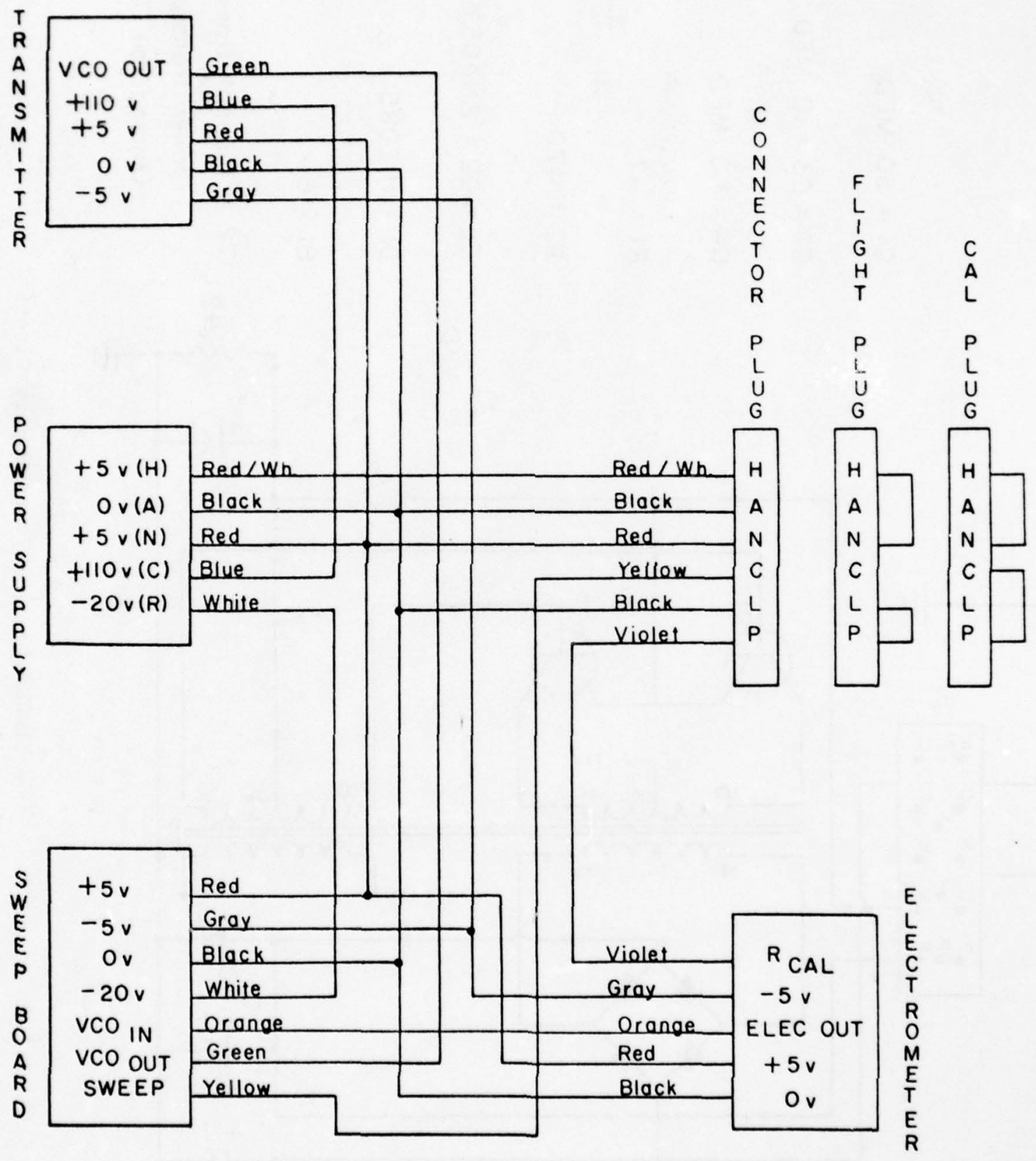

FIGURE (3-3) - Wiring Diagram 


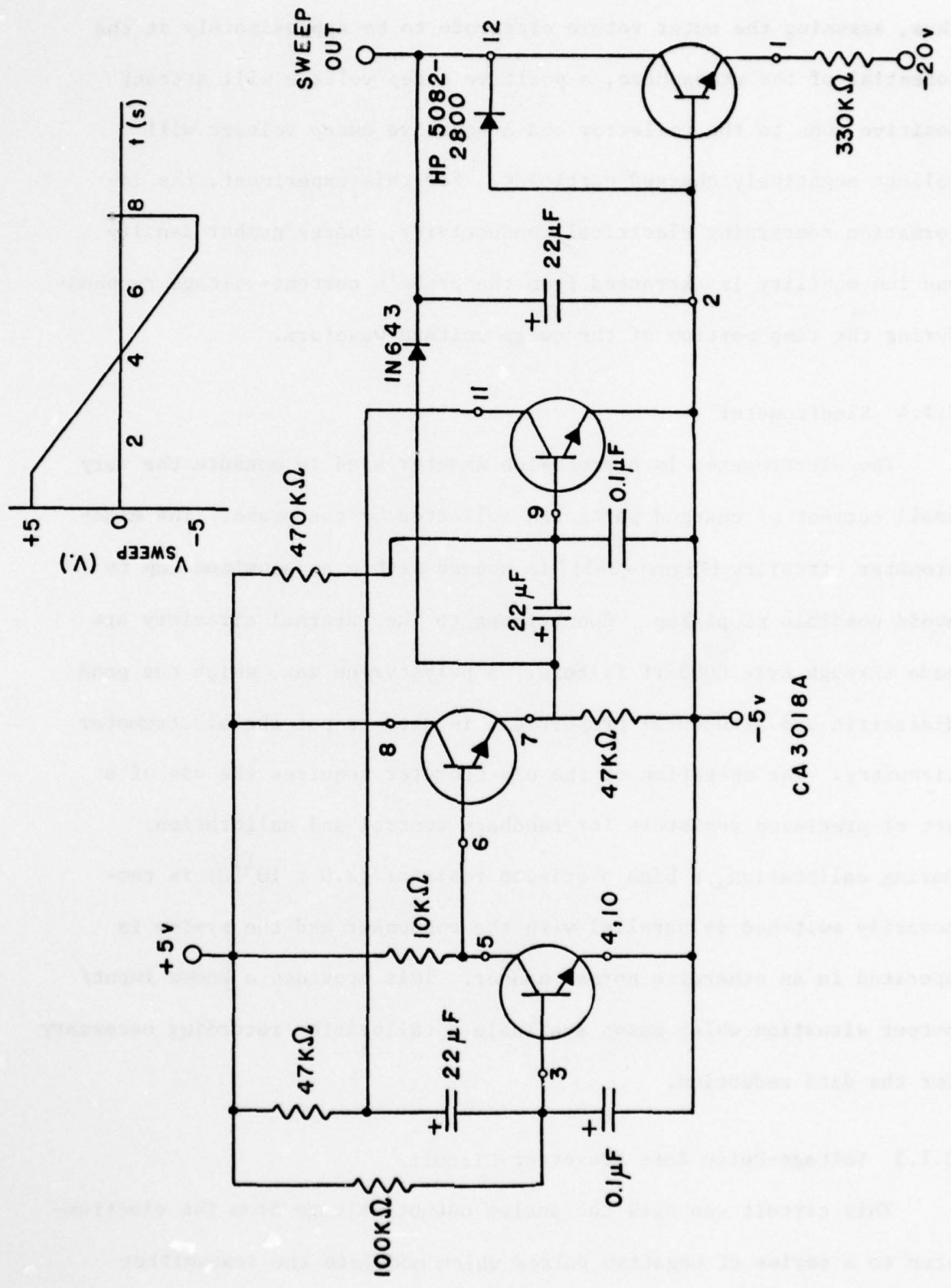

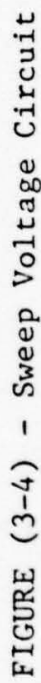


Thus, assuming the outer return electrode to be approximately at the potential of the atmosphere, a positive sweep voltage will attract positive ions to the collector and a negative sweep voltage will collect negatively charged particles. For this experiment, the information concerning electrical conductivity, charge number density and ion mobility is extracted from the probe's current-voltage response during the ramp portion of the sweep voltage waveform.

\subsubsection{Electrometer}

The electrometer is a precision ammeter used to measure the very small current of charged particles collected by the probe. The electrometer c1rcuitry [Figure(3-5)] is housed within an aluminum cup to avoid possible $\mathrm{rf}$ pickup. Connections to the external circuitry are made through Erie E003 rf filters. A polystyrene wax, which has good dielectric and structural properties, is used to pot the electrometer circuitry. The operation of the electrometer requires the use of a set of precision resistors for feedback control and calibration. During calibration, a high precision resistor $\left(2.0 \times 10^{11} \Omega\right)$ is temporarily switched in parallel with the condenser and the system is operated in an otherwise normal manner. This provides a known imput/ output situation which makes available a calibration recording necessary for the data reduction.

\subsubsection{Voltage-Pulse Rate Converter Circuit}

This circuit converts the analog output voltage from the electrometer to a series of negative pulses which modulate the transmitter tube. For the particular circuit in Figure (3-6), the typical range 


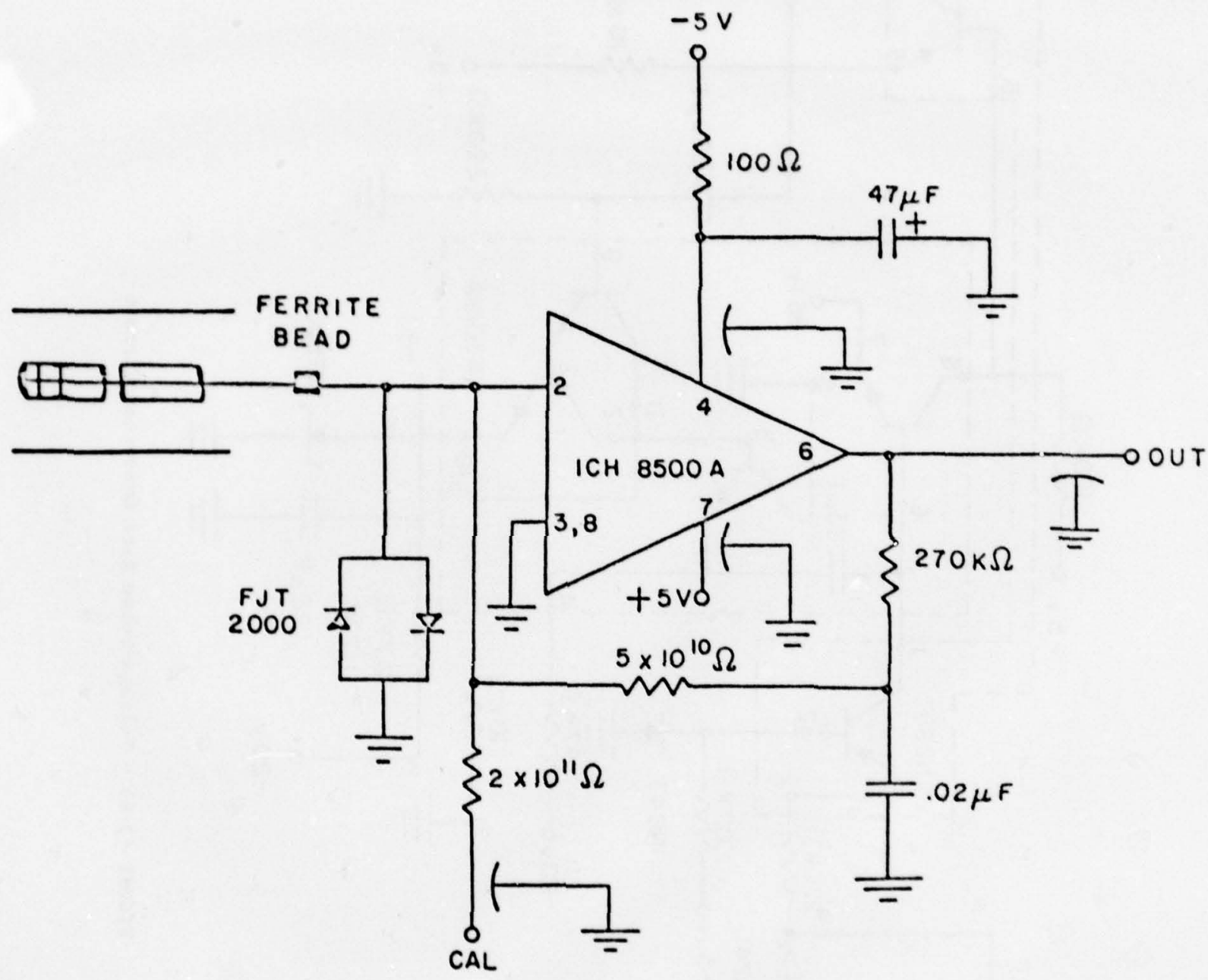

FIGURE (3-3) - Electrometer Cịrcuit 


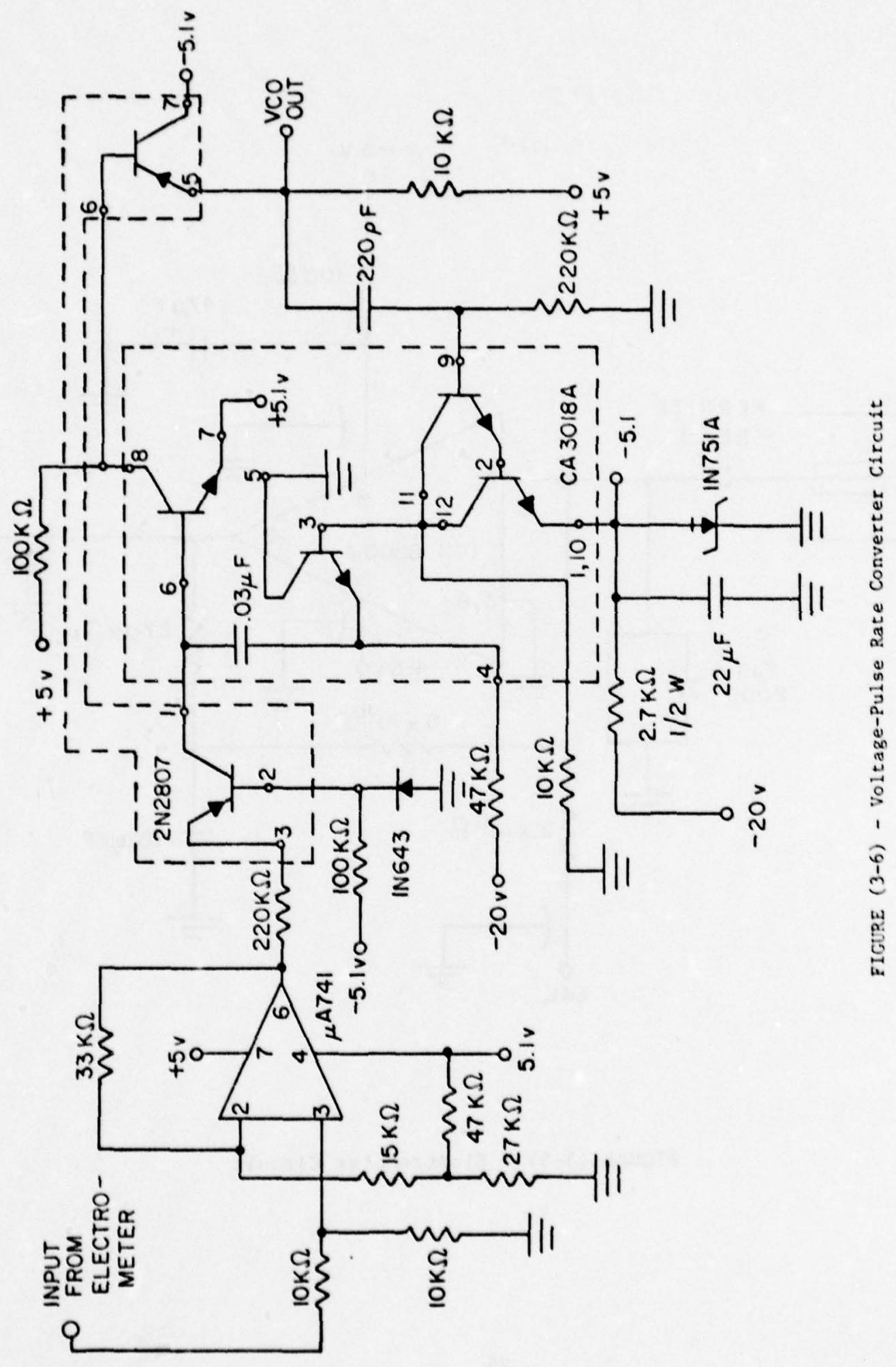


of input voltages from -1.5 to $+1.5 \mathrm{~V}$ corresponds linearly to pulse frequencies from approximately 0 to $200 \mathrm{pps}$. The output, which is capacitively coupled to the grid of the transmitter tube, alternately cuts the tube off thus producing a pulse modulated signal.

\subsubsection{Transmitter and Antenna System}

The transmitter circuit diagram is shown in Figure (3-7). The transmitter is an RCA $4048 \mathrm{~V} 3$ microwave cavity device tunable to a frequency of $1680 \mathrm{MHz}$ with some adjustment $(+20 \mathrm{MIz})$ possible. The output of the transmitter tube is coupled to a $\frac{\lambda}{4}$ circular slot antenna.

\subsection{Mechanical Design}

A schematic of the Gerdien condenser is shown in Figure (3-8). The instrument has been designed for flight on a standard meteorological rocket system such as the Arcas rocket. The complete payload with base plate is $43.2 \mathrm{~cm}$ in length and weighs $2.18 \mathrm{~kg}$. The diameter of the outer return electrode is $7.44 \mathrm{~cm}$, while the collector diameter is $2.22 \mathrm{~cm}$ and is $6.35 \mathrm{~cm}$ in length.

The power supply forms the lower structure of the payload. A base plate for connecting the parachute lanyard is bolted to the bottom of the power supply. The entire power supply is potted with a polycel compound, thus providing electrical isolation as well as adding strength to the power supply structure. The antenna can, which is attached to the top of the power supply, contains the sweep voltage generator, voltage-pulse rate converter and transmitter circuitry. The electrometer is located as shown in Figure (3-8). A delrin spacer is used to interface the collector assembly to the antenna can. For 


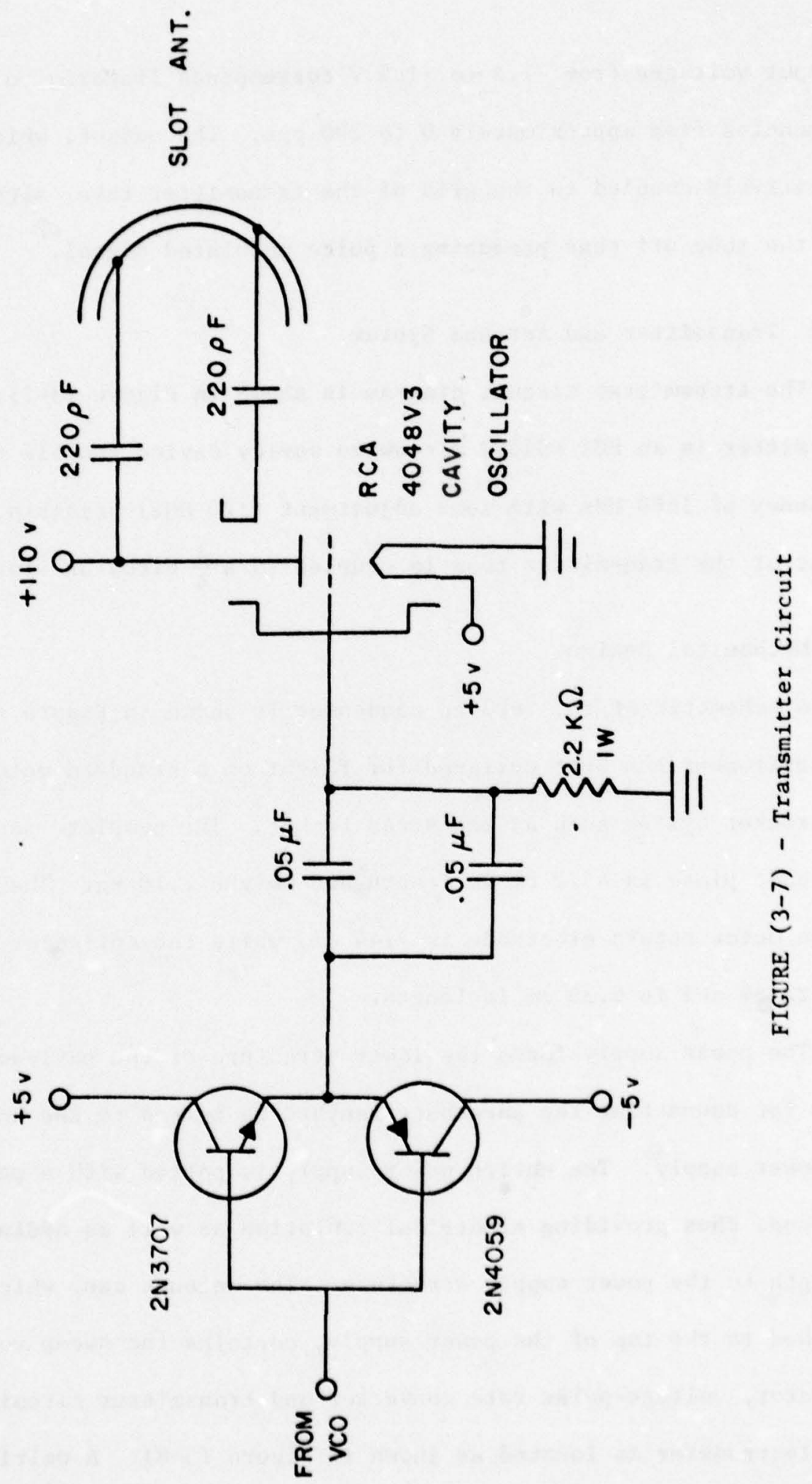




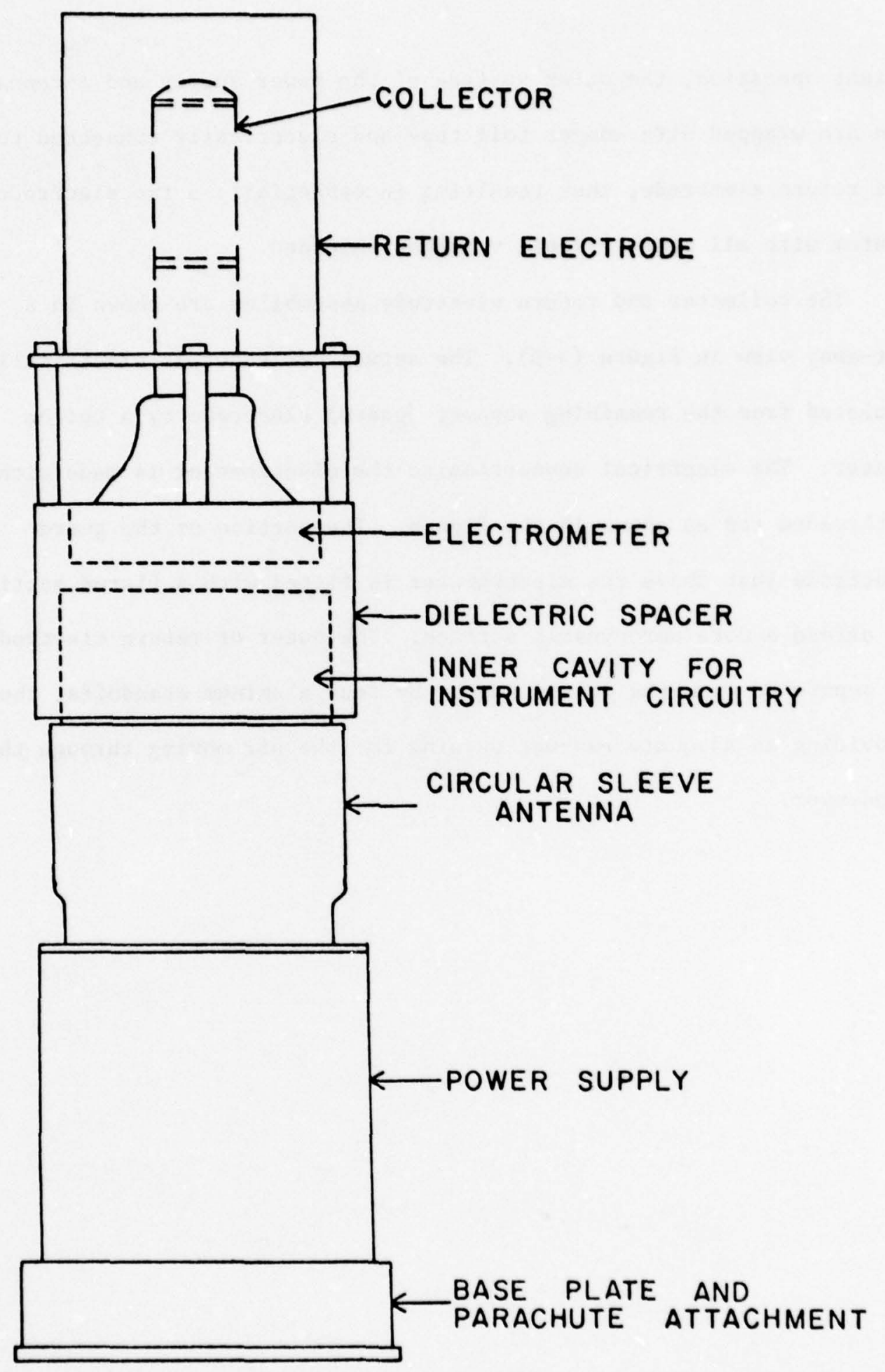

GERDIEN CONDENSER

FIGURE (3-8) 
flight operation, the outer surface of the power supply and antenna can are wrapped with copper foil tape and electrically connected to the return electrode, thus resulting in essentially a two electrode system with all other circuit voltages shielded.

The collector and return electrode assemblies are shown in a cut-away view in Figure (3-9). The actual collector is electrically isolated from the remaining support (guard) electrode by a teflon spacer. The electrical connection to the electrometer is made with a threaded rod as shown in the figure. The portion of the guard electrode just above the electrometer is fitted with a flared section to afford a more aerodynamic surface. The outer or return electrode is separated from the delrin spacer by four aluminum standoffs, thus providing an adequate exhaust opening for the air moving through the condenser. 


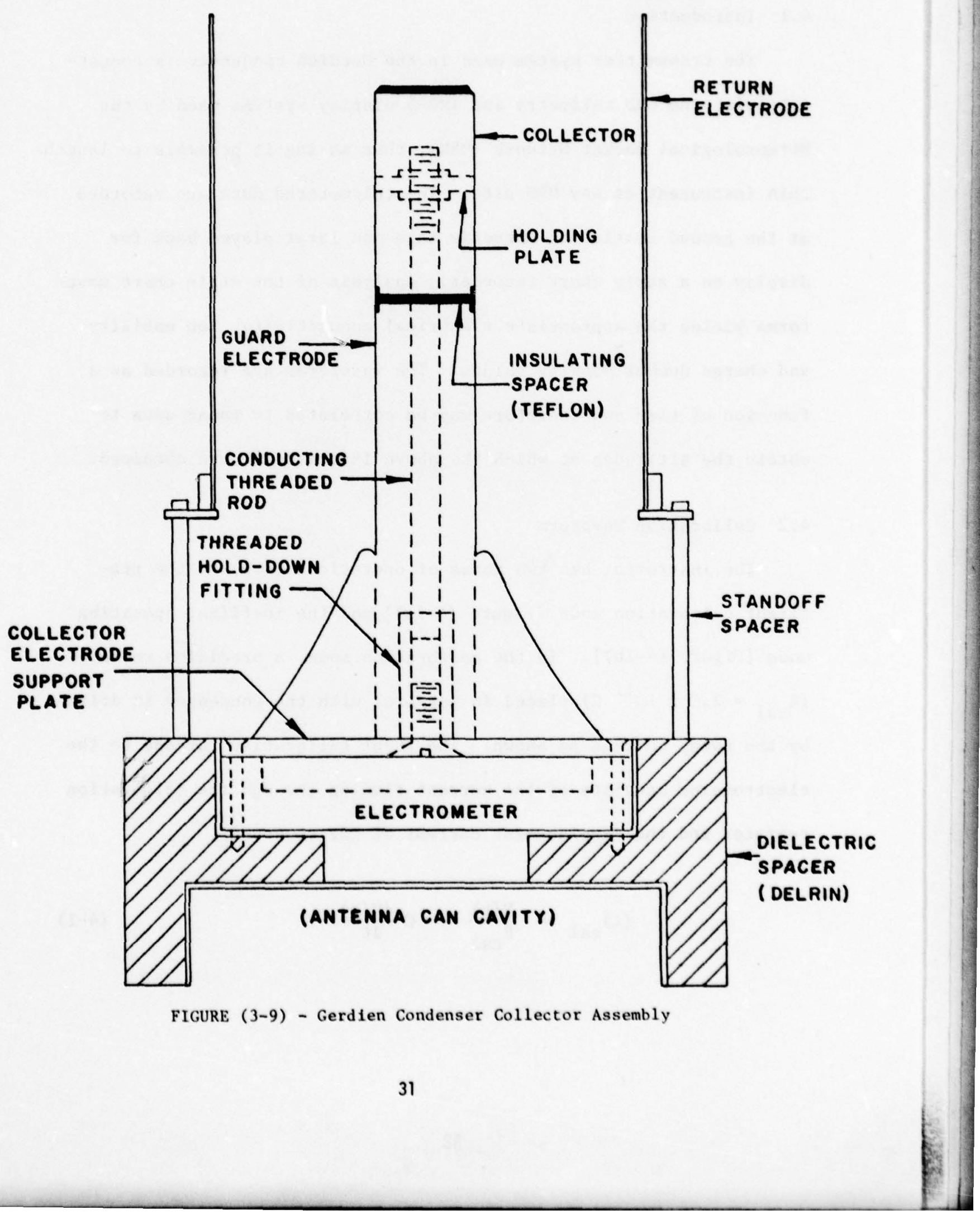




\section{TELEMETRY/DATA ACQUISITION}

\subsection{Introduction}

The transmitter system used in the Gerdien condenser is compatible with the GMD telemetry and TMQ-5 display systems used by the Meteorological Rocket Network (MRN), thus making it possible to launch this instrument at any MRN site. The telemetered data are recorded at the ground station on magnetic tape and later played back for display on a strip chart recorder. Analysis of the strip chart waveforms yields the appropriate electrical conductivity, ion mobility and charge number density values. The waveforms are recorded as a function of time and therefore may be correlated to radar data to obtain the altitudes at which the above information were obtained.

\subsection{Calibration Waveform}

The instrument has two modes of operation. They are the preflight calibration mode [Figure $(4-1 a)$ ] and the in-flight operating mode [Figure (4-1b)]. In the calibration mode, a precision resistor $\left(R_{c a l}=2.0 \times 10^{11} \Omega\right)$ placed in parallel with the condenser is driven by the sweep voltage as shown. The input calibration current to the electrometer consists of the current flowing through the calibration resistor and the displacement current of the condenser.

$$
\text { (i) }{ }_{c a l}=\frac{V(t)}{R_{c a l}}+c \frac{d V(t)}{d t}
$$



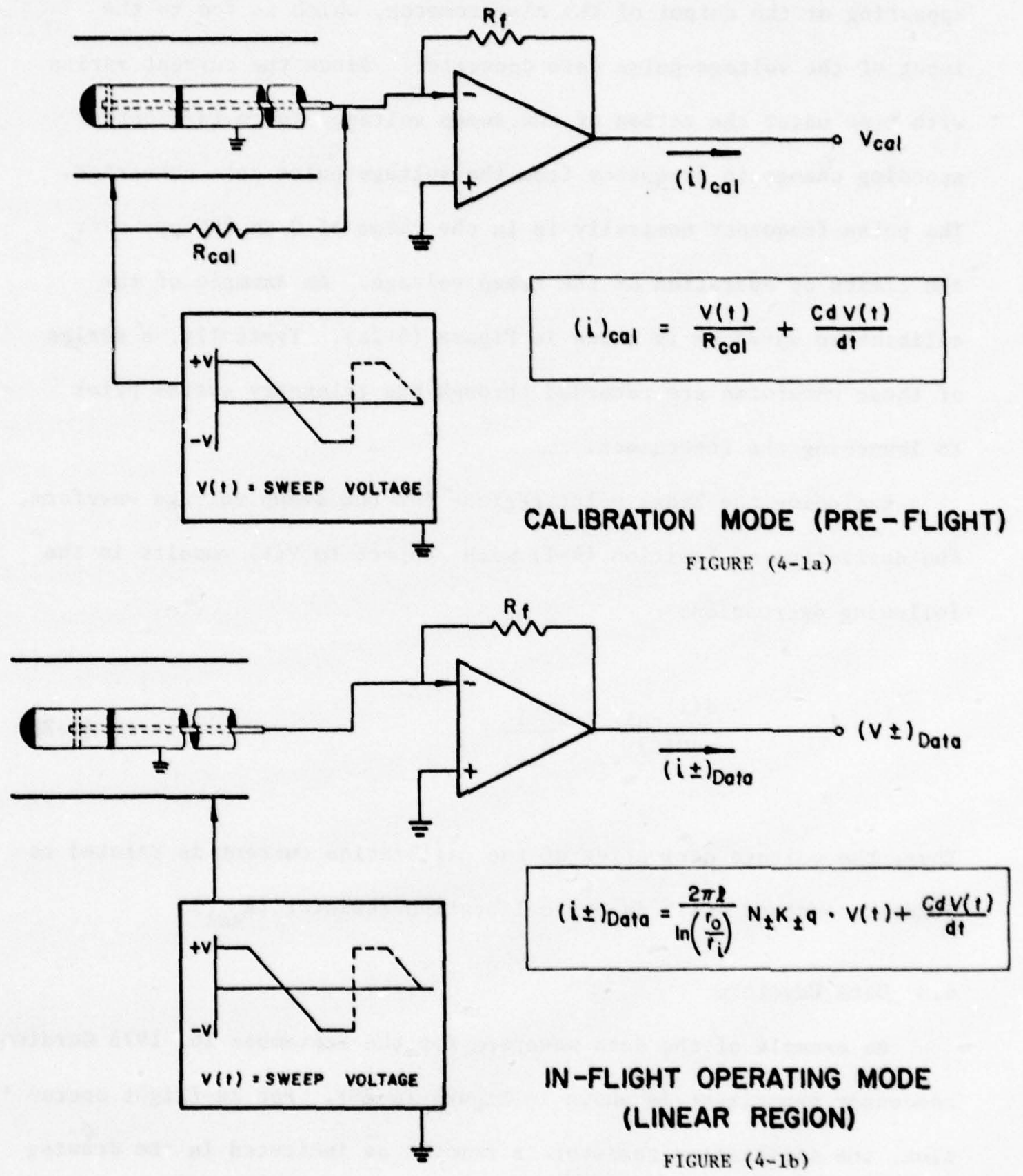
The result of this current is the calibration voltage $\left(v_{c a 1}\right)$ appearing at the output of the electrometer, which is fed to the input of the voltage-pulse rate converter. Since the current varies with time under the action of the sweep voltage, there is a corresponding change in frequency from the voltage-pulse rate converter. The pulse frequency nominally is in the range of 0 to $200 \mathrm{pps}$ over the limits of operation of the sweep voltage. An example of the calibration waveform is shown in Figure $(4-2 a)$. Typically, a series of these waveforms are recorded through the telemetry system prior to launching the instrument.

Excluding the break point regions for the sweep voltage waveform, the derivative of Equation $(4-1)$ with respect to $V(t)$ results in the following expression:

$$
\frac{d(i) \text { cal }}{d V(t)}=\frac{1}{R_{c a l}}
$$

Thus, the veltage derivative of the calibration current is related to a known constant which is the calibration resistor $\left(R_{c a l}\right)$.

\subsection{Data Waveform}

An example of the data waveform for the September 26, 1975 Gerdien condenser experiment is shown in Figure $(4-2 b)$. For in-flight operation, the calibration resistor is removed as indicated in the drawing [Figure (4-1b)]. The input current to the electrometer while in flight consists of the current due to charged particle collection and the condenser displacement current. Using Equation $(2-4)$, the 


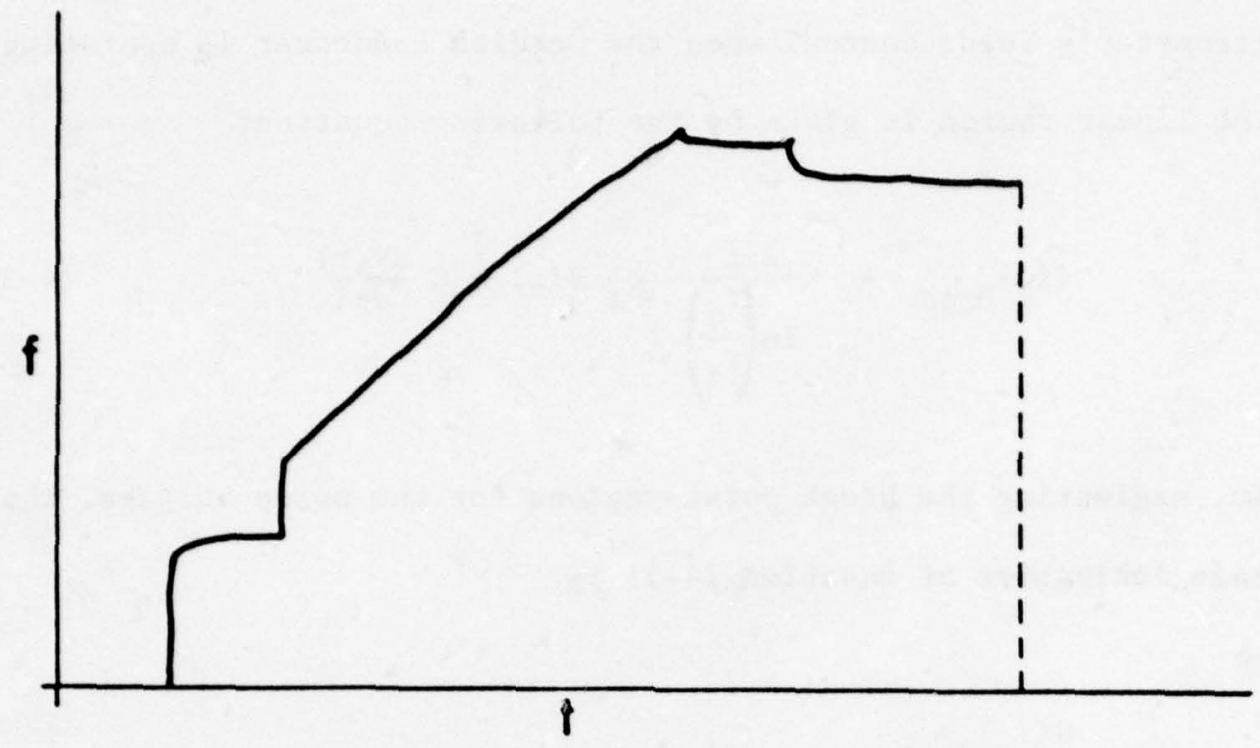

RECEIVED CALIBRATION WAVEFORM

FIGURE (4-2a)

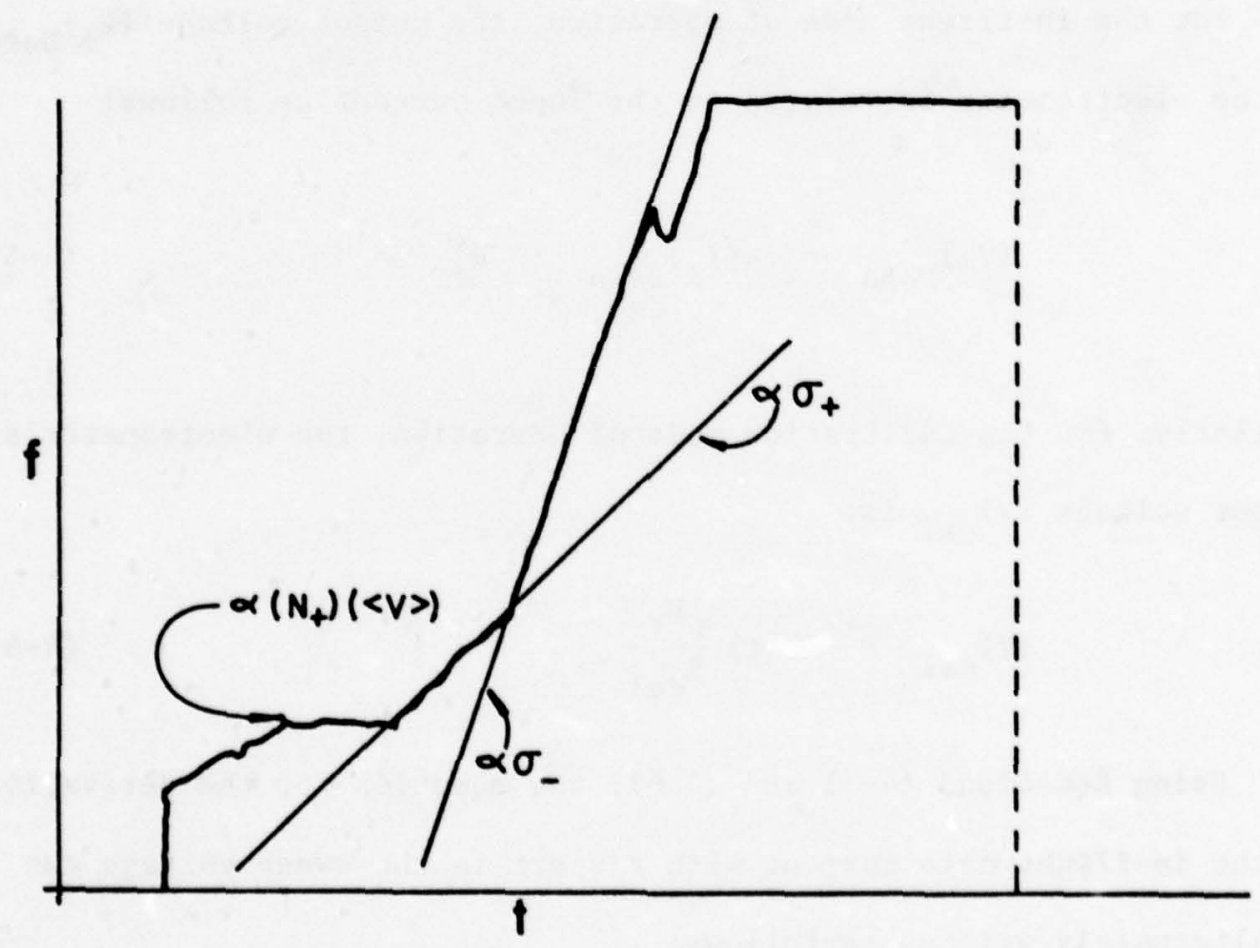

RECEIVED DATA WAVEFORM

FIGURE $(4-2 b)$ 
electrometer's input current when the Gerdien condenser is operating in the linear region is given by the following equation:

$$
\left(i_{ \pm}\right)_{\text {Data }}=\frac{2 \pi l}{\ln \left(\frac{r_{0}}{r_{i}}\right)} \sigma_{ \pm} v(t)+c \frac{d V(t)}{d t}
$$

Again, neglecting the break point regions for the sweep voltage, the voltage derivative of Equation $(4-3)$ is:

$$
\frac{d\left(i_{ \pm}\right) \text {Data }}{d V(t)}=\frac{2 \pi l}{\ln \left(\frac{r_{0}}{r_{i}}\right)} \sigma_{ \pm}
$$

\subsection{Data Reduction}

For the in-flight mode of operation, the output voltage $\left(\mathrm{V}_{ \pm}\right)$Data of the electrometer is related to the input current as follows:

$$
\left(v_{ \pm}\right)_{\text {Data }}=-\left(i_{ \pm}\right)_{\text {Data }} \cdot R_{f}
$$

Similarly, for the calibration made of operation, the electrometer's output voltage $(\mathrm{V})_{\mathrm{cal}}$ is:

$$
(v)_{c a 1}=-V(t) \frac{R_{f}}{R_{c a 1}}
$$

Using Equations (4-5) and (4-6), the equation for the derivative of the in-flight data current with respect to the sweep voltage can be alternately written as follows: 


$$
\frac{d\left(1_{ \pm}\right)_{\text {Data }}}{d V(t)}=\frac{1}{R_{\text {cal }}} \frac{\left(\frac{d V_{ \pm}}{d t}\right)_{\text {Data }}}{\left(\frac{d V}{d t}\right)_{\text {cal }}}
$$

Combining Equations $(4-2),(4-4)$ and $(4-7)$ yields the expression which may be used in the linear region to determine electrical conductivity:

$$
\sigma_{ \pm}=\frac{\ln \left(\frac{\mathrm{r}_{0}}{\mathrm{r}_{i}}\right)}{2 \pi \ell \mathrm{R}_{\mathrm{cal}}} \frac{\left(\frac{\mathrm{dv_{ \pm }}}{\mathrm{dt}}\right)_{\text {Data }}}{\left(\frac{\mathrm{dV}}{\mathrm{dt}}\right)_{\mathrm{ca} 1}}
$$

Since the voltage-pulse rate converter linearly converts the electrometer output to a pulse frequency for modulating the transmitter, Equation (4-8) can be written in terms of the transmitter's pulse frequency as follows:

$$
\sigma_{ \pm}=\frac{\ln \left(\frac{\mathrm{r}_{\mathrm{o}}}{\mathrm{r}_{i}}\right)}{2 \pi \ell R_{\mathrm{cal}}} \frac{\left(\frac{\mathrm{df}_{ \pm}}{\mathrm{dt}}\right)_{\text {Data }}}{\left(\frac{\mathrm{df}}{\mathrm{dt}}\right)_{\text {cal }}}
$$

Equation (4-9) is used to extract the electrical conductivity information from the telemetered data waveforms. An example of how the waveform is scaled to obtain the electrical conductivity values is shown in Figure $(4-2 b)$.

The ion mobility and charge number density are obtained from the data waveform by evaluating either the saturation voltage $\left(v_{s \pm}\right)$ or 
the saturation current $\left(1_{1}\right)$. Figure $(4-2 b)$ 1llustrates the point of saturation (break point) for the positive ion current. In this example, only one break point is present in the positive ion curve, thus Indicating that one positive ion mobility group was completely collected by the instrument. For the portion of the data waveform representing the collection of negatively charged particles, the apparent break point observed is not due to saturation but rather is associated with the break in the sweep voltage. The absence of any saturation break point perhaps indicates that the collection voltage was not large enough to collect all of the negative lons moving through the aspirator. 


\section{MEASUREMENTS AND DISCUSSION}

\subsection{Introduction}

The inftial Gerdien condenser flights were conducted at White Sands Missile Range (WSMR), New Mexico $\left(32^{\circ} \mathrm{N}, 106^{\circ} \mathrm{W}\right)$ on July 15,1975 at 0618 MST and September 26, 1975 at 0600 MST. The same instrument was flown on both of these occasions. Launch parameters for these two experiments, as well as for two previous early morning blunt probe flights conducted at WSMR [Mitchell (1973); Mitchell and Hale (1973)], are listed in Table (5-1). The two blunt probe experiments measured only electrical conductivity.

\subsection{Data}

The positive ion conductivity profiles for the Gerdien condenser and blunt probe experiments are shown in Figure (5-1). These four curves represent the most recent early morning profiles (solar zenith angles in the range of $90^{\circ}$ to $53^{\circ}$ ) for the WSMR launch site.

Although the data were obtained over approximately a four-year period, variations in ionization should be relatively small in the region below $60 \mathrm{~km}$ where the production of fons is primarily attributed to galactic cosmic rays. This is demonstrated by the consistency of the conductivity values at $30 \mathrm{~km}$, thus indicating relatively small differences associated with seasonal and diurnal variations as well as different measurement techniques.

For the Gerdien condenser flights, the positive fon mobility data and corresponding charge number densities are plotted in Figures (5-2) and $(5-3)$, respectively. The shaded and 11 ght circles indicate that two distinct Ion mobility groups were measured on September 26 , with the 


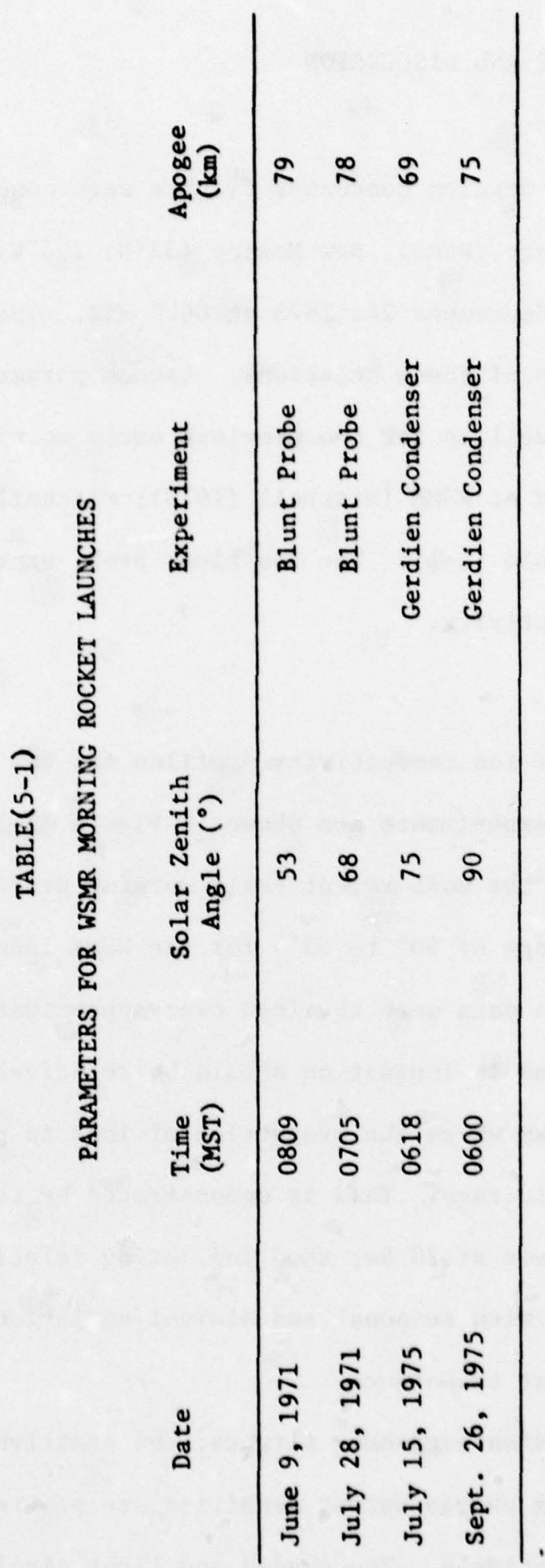




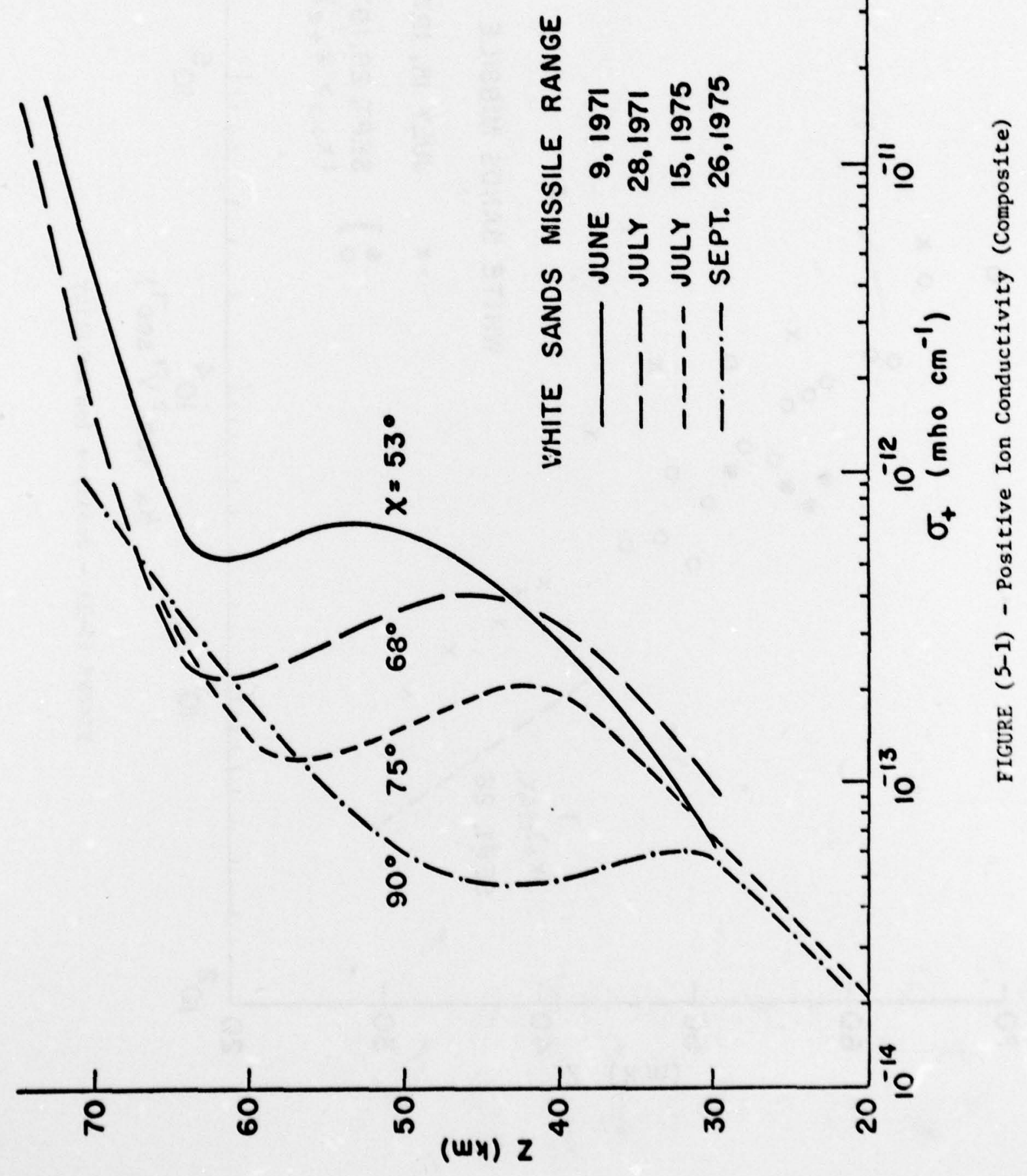




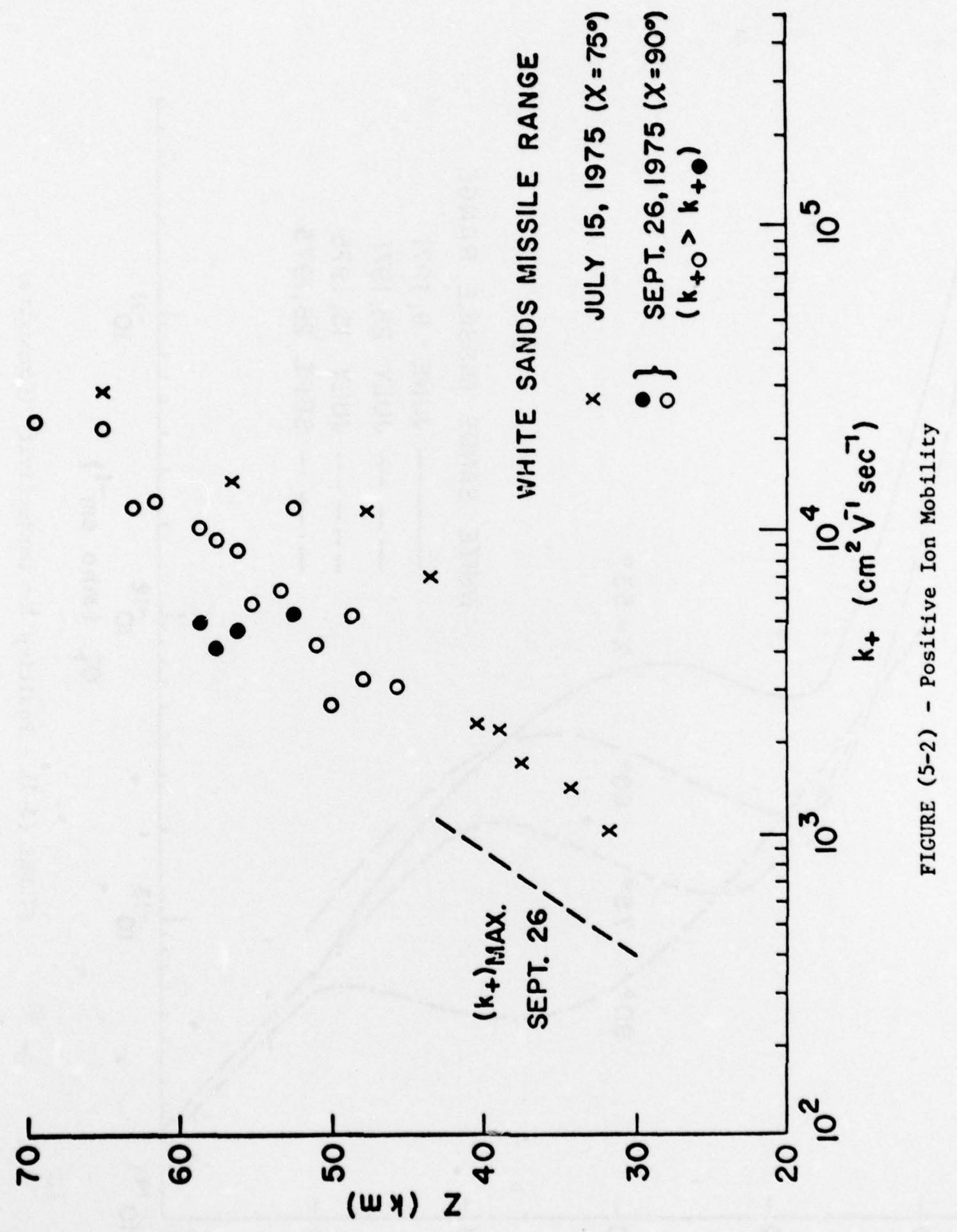




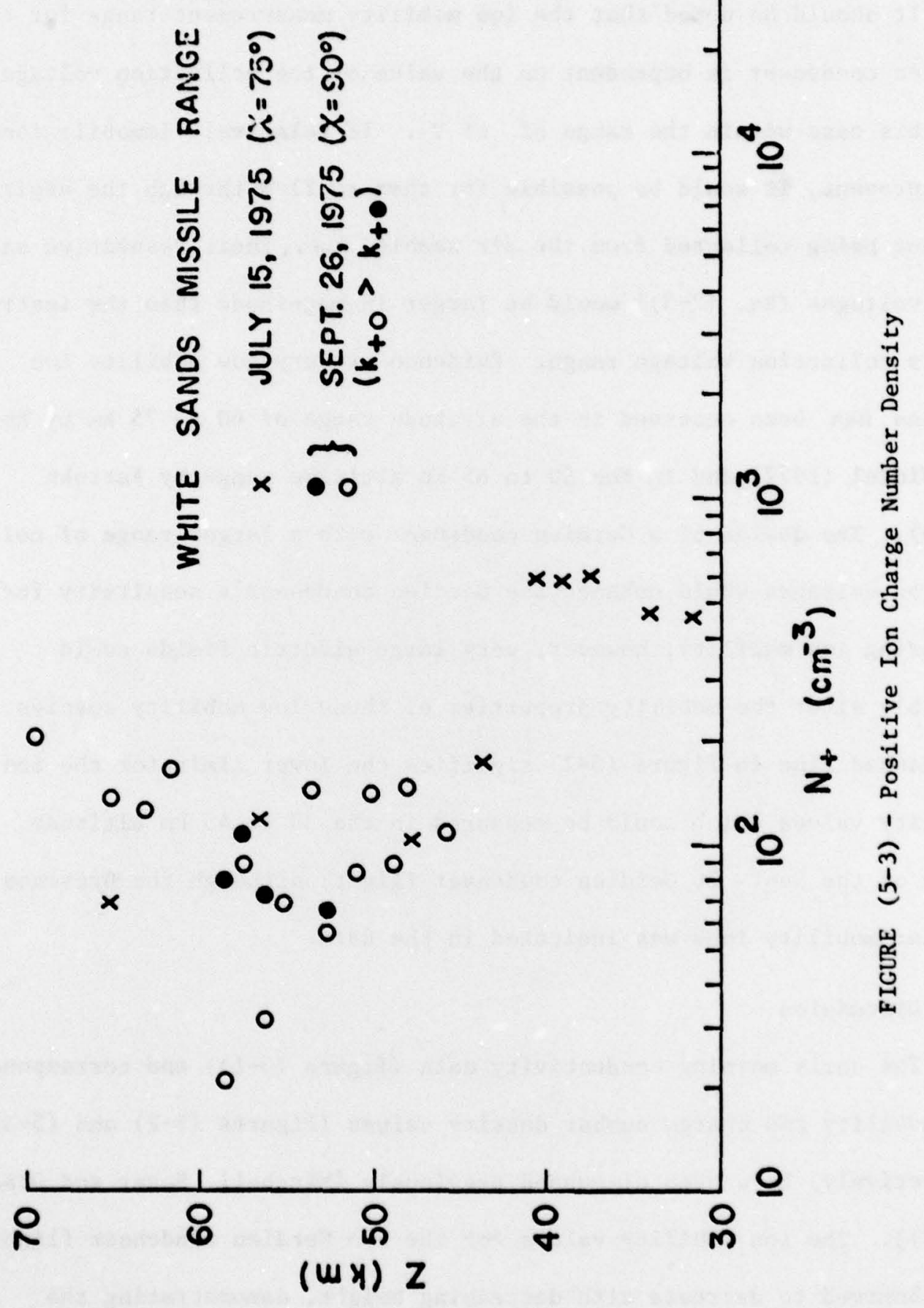


shaded circles representing the smaller mobility values.

It should be noted that the ion mobility measurement range for the Gerdien condenser is dependent on the value of the collection voltage (In this case within the range of $\pm 5 \mathrm{~V}$ ). If relatively immobile ions were present, it would be possible for them to flow through the aspirator without being collected from the air sample, i.e., their respective saturation voltages (Eq. $(2-5)$ ) would be larger in magnitude than the instrument's collection voltage range. Evidence of very low mobility ion species has been observed in the altitude range of 60 to $75 \mathrm{~km}$ by Rose and W1ddel (1972) and in the 50 to $65 \mathrm{~km}$ altitude range by Farrokh (1975). The design of a Gerdien condenser with a larger range of co1lection voltages would enhance the Gerdien condenser's sensitvity for measuring lon mobillty; however, very large electric fields could possibly alter the mobility properties of these low mobility species. The dashed line in Figure (5-2) signifies the lower limit for the ion mobllity values which could be measured in the 30 to $45 \mathrm{~km}$ altitude range on the Sept. 26 Gerdien condenser flight, although the presence of smaller mobility ions was indicated in the data.

\subsection{Discussion}

The early morning conductivity data (Figure (5-1)) and corresponding Ion mobility and charge number density values (Figures (5-2) and (5-3) respectively) have been discussed previously [Mitchell, Sagar and 01sen (1977)]. The Ion mobility values for the two Gerdien condenser flights are observed to decrease with decreasing helght, demonstrating the altitude dependence of this parameter. A change in lon mobility with respect to altitude is particularly evident between 40 and $45 \mathrm{~km}$, 
suggesting a transition in fon mobility groups. A simflar observation was reported by Rose and Widdel (1972). It should be noted that this transition region also corresponds to the region where Arnold, Krankowsky and Marien (1977) observe a change in positive ion composition from proton hydrates (at higher altitudes) to non-proton hydrates (at lower a1titudes).

of noted interest is the observed buildup in positive ion conductivity, particularly in the 35 to $55 \mathrm{~km}$ altitude region where the production mechanism for positive ions (galactic cosmic ray ionization) has little diurnal or seasonal dependence [Velínov (1968)]. Conductivity enhancements of at least an order of magnitude were observed between 45 and $50 \mathrm{~km}$, corresponding to a change in solar zenith angle from $90^{\circ}$ to $53^{\circ}$. A conductivity change of this size is not believed to be explainable by a change in ionization, and recent studies of temperature-dependent variations for midday positive conductivity values demonstrate at most a change of $4.6 \% /{ }^{\circ} \mathrm{K}$ for this altitude region [Cipriano, Hale and Mitchell (1974)].

A comparison of the Ion mobility data for the two Gerdien condenser experiments indicates that the values for July $15\left(x=75^{\circ}\right)$ are approximately a factor of two larger than the corresponding values for September $26\left(x=90^{\circ}\right)$, while the corresponding ion number density values are comparable. Thus, the buildup in positive ion conductivity observed between the change in morning solar zenith angle from $90^{\circ}$ to $75^{\circ}$ appears to be primarily associated with an increase in ion mobility. Such behavior is thought to be explainable by a photodissociation process resulting in the formation of smaller, more mobile lons. The solar dependence for positive conductivity is better demon- 
strated in Figure $(5-4)$ where the secant of the solar zenith angle $(x)$

is ploted as a function of conductivity for different altitudes.

Electrical conductivity data obtained later in the morning $\left(x=44^{\circ}\right)$

showed no further enhancement in value, thus suggesting that this

phenomenon is limited to the early morning period.

Finally, it should be noted that the two Gerdien condenser flights

present a somewhat limited picture of the early morning ionization

processes since they correspond to solar zenith angles of $90^{\circ}$ and $75^{\circ}$.

As demonstrated in Figure (5-1), a continued positive conductivity

buildup was observed through a solar zenith angle of $53^{\circ}$, during

which no corresponding ion mobility and number density measurements

were made. The mechanism (ion mobility and/or number density) for this

extended conductivity buildup is thus unknown, and is proposed as a

subject for further study. Also, recalling that the data used in this

report covered a four-year period, a further study should be conducted

using measurements obtained over a relatively shorter time frame

(preferably on the order of days) and also repeated for periods of

different solar activity. 


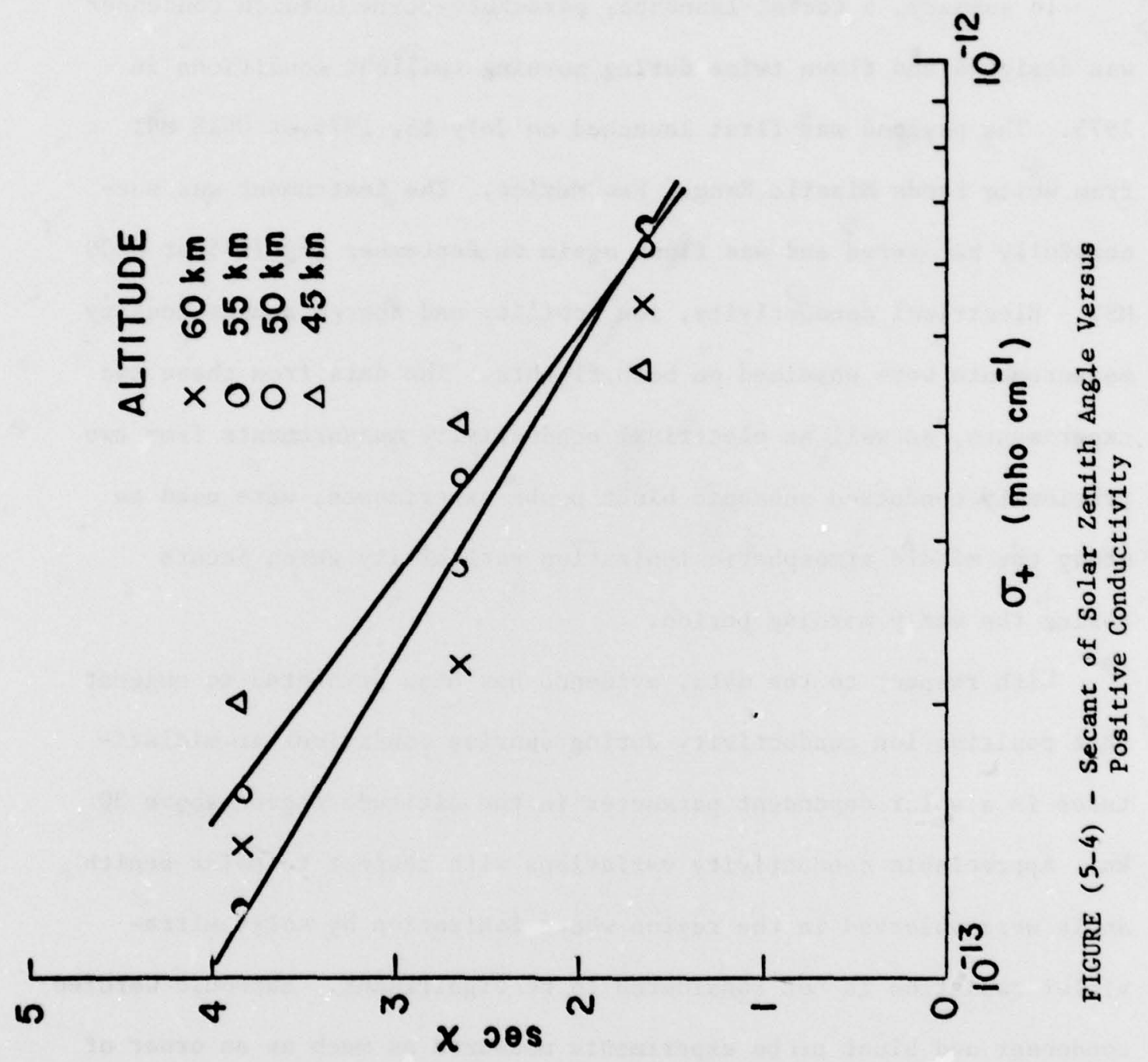




\section{CONCLUSIONS AND RECOMMENDATIONS}

\subsection{Conclusions}

In summary, a rocket-launched, parachute-borne Gerdien condenser was designed and flown twice during morning twilight conditions in 1975. The payload was first launched on fuly 15, 1975 at 0618 MST from White Sands Missile Range, New Mexico. The instrument was successfully recovered and was flown again on September 26, 1975 at 0600 MST. Electrical conductivity, ion mobility and charge number density measurements were obtained on both flights. The data from these two experiments, as well as electrical conductivity measurements from two previously conducted subsonic blunt probe experiments, were used to study the middle atmospheric fonization variability which occurs during the early morning period.

With respect to the data, evidence has been presented to suggest that positive ion conductivity during sunrise conditions at midlatitudes is a solar dependent parameter in the altitude region above 30 $\mathrm{km}$. Appreciable conductivity varlations with respect to solar zenith angle were observed in the region where ionization by solar ultraviolet radiation is not considered to be significant. Subsonic Gerdien condenser and blunt probe experiments measured as much as an order of magnitude increase in ion conductivity at certain altitudes $(45 \mathrm{~km}$ to $50 \mathrm{~km}$ ) over a change in solar zenith angle from $90^{\circ}$ to $53^{\circ}$. Ion mobility data from the Gerdien condenser experiments indicated that the increase in ion conductivity primarily resulted from an increase In Ion mobility, thus suggesting the presence of a photodissociation 
process for positive ions during the early morning period which results in smaller, more mobile ions.

\subsection{Recommendations}

More than one distinct positive ion mobility group were observed in some of the Gerdien condenser data for September 26, 1975. The instrument's ability to measure the smaller mobility species is to a significant exţent dependent upon the size of the collection voltage, and thus a larger range of sweep voltages should be considered for future Gerdien condenser experiments.

The data handling and reduction capabilities could be greatly improved by the implementation of computer analysis techniques. The telemetered data format is the same for both the Gerdien condenser and the blunt probe and thus, with a greater usage anticipated for both of these instruments, the development of such computer software would be very beneficial.

Finally, the implications of using mobility data to interpret ion mass and size are beyond the scope of this thesis, but merit further consideration. A better understanding of the dependence of ion mobility on these parameters would be potentially helpful in further studying the ionization processes in the middle atmosphere. 


\section{REFERENCES}

Arnold, F., D. Krankowsky and K. H. Marien, First mass spectrometric measurements of positive ions in the stratosphere, Nature 267, 30-32 (1977).

Chesworth, E. T. and L. C. Hale, Ice particulates in the mesophere, Geophys. Res. Lett. 1, 347-350 (1974).

Cipriano, J. P., L. C. Hale and J. D. Mitchell, Relations among low Ionosphere parameters and $\mathrm{A} 3$ radio wave absorption, J. Geophys.

Res. 79, 2260-2265 (1974).

Conley, T.D., Mesospheric positive ion concentration mobility and loss rates obtained from rocket-borne Gerdien condenser measurements, Radio Sc1. 9, 575-592 (1974).

Croskey, C., In situ measurements of the mesosphere and stratosphere, Scientific Report No. 442, Ionosphere Research Laboratory, The Pennsylvania State University (1976).

Cuffin, N., A circular slot antenna for use on ionospheric probes, Scientific Report No. 249, Ionosphere Research Laboratory, The Pennsylvania State University (1965).

ECOM Report No. 5144 , U.S. Army Electronics Command, Atmospheric Sciences Laboratory, White Sands Missile Range, New Mexico (1967).

Farrokh, H., Design of a simple Gerdien condenser for ionospheric D-region charged particle density and mobility measurements, Sclentific Report No. 433, Ionosphere Research Laboratory, The Pennsylvania State University (1975).

Gerdien, H., Demonstration eines apparates zur absoluten messung der electreschen leitfahigut der luft, Terr. Magn. Atmos. Elec. 10, 65-79 (1905).

Hale, L. C. and D. P. Hoult, A subsonic D-region probe-theory and Instrumentation, Scientific Report No. 247, Ionosphere Research Laboratory, The Pennsylvania State University (1965).

Israel, H. and L. Schulz, The mobility spectrum of atmospheric Ions-principles of measurements and results, Terr. Magn. Atmos. Elec. 38, 285-300 (1933).

Kraakevik, J., The airborne measurement of atmospheric conductivity, J. Geophys. Res. 63, 161-169 (1958).

Mitchell, J. D., An experimental investigation of mesospheric Ionization, Scientific Report No. 416, Ionosphere Research Laboratory, The Pennsylvania State Unive sity (1973). 
Mitchell, J. D. and L. C. Hale, Observations of the lowest loncsphere, Space Research XIII, 471-475 (1973).

Mitche11, J. D., R. S. Sagar and R. 0. 01sen, Positive fons in the middle atmosphere during sunrise conditions, Space Research XVII, 199-204 (1977).

Paltridge, G. W., Experimental measurement of the smal1-ion density and electrical conductivity of the stratosphere, J. Geophys. Res. 70, 2751-2761 (1965).

Pedersen, A., Measurement of Ion concentration in the D-region of the Ionosphere with a Gerdien condenser rocket probe, FOA 3 Report A607, Research Institute of National Defence, Stockholm, Sweden (1964).

Pontano, B. A., Rocket measurements of Nitric oxide in the lower D-region of the ionosphere, Scientific Report No. 347, Ionosphere Research Laboratory, The Pennsylvania State University (1970).

Rose, G. and H. U. Widdel, Results of concentration and mobility measurements for positively and negatively charged particle taken between 85 and $22 \mathrm{~km}$ in sounding rocket experiments, Radio Sc1. 7, 81-87 (1972).

Stergis, C. G., S. C. Coroniti, A. Nazarek, D. E. Kotas, D. W. Seymour and J. V. Werme, Conductivity measurement in the stratosphere, J. Atmos. Terr. Phys. 6, 233-242 (1955).

Velinov, P., On fonization in the ionospheric D-region by galactic cosmic rays, J. Atmos. Terr. Phys. 30, 1891-1905 (1968).

Widdel, H. U., private communication (1975).

Widdel, H. U., G. Rose and R. Borchers, The variation of electric conductivity and ion mobility in the mesosphere between high and low solar activity measured with a rocket borne parachute Gerdien aspiration analyzer probe experiment, Report No. MPAE-W-47-76-09, Max-Planck-Institut Fur Aeromonie (1976).

Woessner, R. H., W. E. Cobb and R. H. Gunn, Simultaneous measurement of the positive and negative 11 ght-ion conductivities to 26 kilometers, J. Geophys. Res. 63, 171-180 (1958).

Z1mmerman, L. E., Integrated c1rcuit electrometer and sweep circuitry for an atmospheric probe, Scientific Report No. 376 (E), Ionosphere Research Laboratory, The Pennsylvania State University (1971).

Bourdeau, R. E., E. C. Whipple, Jr. and J. F. Clark, Analytic and experimental electrical conductivity between the stratosphere and Ionosphere, J. Geophys. Res. 64, 1363-1370 (1959). 